\title{
Hematopoietic AMPK $\beta 1$ reduces mouse adipose tissue macrophage inflammation and insulin resistance in obesity
}

\author{
Sandra Galic, ${ }^{1}$ Morgan D. Fullerton, ${ }^{2}$ Jonathan D. Schertzer, ${ }^{2}$ Sarah Sikkema, ${ }^{2}$ \\ Katarina Marcinko,2 Carl R. Walkley, ${ }^{1}$ David Izon, ${ }^{1}$ Jane Honeyman,1 Zhi-Ping Chen, ${ }^{1}$ \\ Bryce J. van Denderen, ${ }^{1}$ Bruce E. Kemp, ${ }^{1}$ and Gregory R. Steinberg ${ }^{1,2}$ \\ ${ }^{1}$ St. Vincent's Institute of Medical Research, University of Melbourne, Fitzroy, Victoria, Australia. \\ ${ }^{2}$ Division of Endocrinology and Metabolism, Department of Medicine, McMaster University, Hamilton, Ontario, Canada.
}

\begin{abstract}
Individuals who are obese are frequently insulin resistant, putting them at increased risk of developing type 2 diabetes and its associated adverse health conditions. The accumulation in adipose tissue of macrophages in an inflammatory state is a hallmark of obesity-induced insulin resistance. Here, we reveal a role for AMPK $\beta 1$ in protecting macrophages from inflammation under high lipid exposure. Genetic deletion of the AMPK $\beta 1$ subunit in mice (referred to herein as $\beta 1^{-/-}$mice) reduced macrophage AMPK activity, acetyl-CoA carboxylase phosphorylation, and mitochondrial content, resulting in reduced rates of fatty acid oxidation. $\beta 1^{-/-}$macrophages displayed increased levels of diacylglycerol and markers of inflammation, effects that were reproduced in WT macrophages by inhibiting fatty acid oxidation and, conversely, prevented by pharmacological activation of AMPK $\beta 1$-containing complexes. The effect of AMPK $\beta 1$ loss in macrophages was tested in vivo by transplantation of bone marrow from WT or $\beta 1^{-/-}$mice into WT recipients. When challenged with a high-fat diet, mice that received $\beta 1^{-/}$bone marrow displayed enhanced adipose tissue macrophage inflammation and liver insulin resistance compared with animals that received WT bone marrow. Thus, activation of AMPK $\beta 1$ and increasing fatty acid oxidation in macrophages may represent a new therapeutic approach for the treatment of insulin resistance.
\end{abstract}

\section{Introduction}

Obesity is associated with increased production of inflammatory cytokines, which are important contributing factors to the development of insulin resistance (1) and defects in fatty acid metabolism (2). In obesity, macrophages accumulate in adipose tissue and are in an inflammatory state, and they are the major source of systemic low-grade inflammation (3-5). In mice, this macrophage inflammation is mediated by the activation of the inflammatory serine/threonine kinases inhibitor of $\kappa \mathrm{B}$ kinase (IKK) and JNK and is critical for the development of obesity/high-fat diet-induced (HFD-induced) insulin resistance $(6,7)$.

The M1 activation of macrophages, rendering them inflammatory, is mediated in part by members of the TLR family, which sense not only microbial pathogens but also saturated fatty acids that are commonly elevated in obese humans (8-10). Indeed, mice with hematopoietic deletion of TLR 4 are partially protected from developing obesity-related inflammation and insulin resistance (11).

In addition to TLR signaling, the lipid content of macrophages may also be important for regulating inflammation. Total macrophage lipid content is increased in obese rodents fed HFD, and this is associated with M1 activation $(12,13)$. Furthermore, mice deficient in regulators of fatty acid oxidation and mitochondrial capacity including PPAR $\gamma(14,15)$, PPAR $(16,17)$, and PPAR $\gamma$ coactivator-1 $\beta$ (PGC1 $\beta$ ) (18) have an increased propensity for developing

Authorship note: Sandra Galic and Morgan D. Fullerton contributed equally to this work.

Conflict of interest: The authors have declared that no conflict of interest exists.

Citation for this article: J Clin Invest. 2011;121(12):4903-4915. doi:10.1172/JCI58577. lipid-induced inflammation and insulin resistance. Similarly, deletion of the fatty acid-binding protein $\mathrm{aP} 2$ or $\mathrm{aP} 2$ inhibitor protects mice against the development of obesity-related inflammation, insulin resistance, and atherosclerosis $(19,20)$. Recent studies in which diacylglycerol (DAG) acyltransferase was overexpressed in hematopoietic cells suggest that the total macrophage lipid content may be less important than the specific lipid species involved and that reductions in DAG may be important for preventing lipidinduced activation of inflammatory signaling (21).

The activation of AMPK acutely increases fatty acid oxidation and suppresses fatty acid synthesis through phosphorylation of acetyl-CoA carboxylase (ACC) (ref. 22; reviewed in ref. 23). AMPK also helps control fatty acid oxidation through regulation of total mitochondrial content (24-26), effects mediated through phosphorylation and deacetylation of PGC-1 $\alpha(27,28)$. In skeletal muscle, the chronic activation of AMPK by cytokines increases mitochondrial content and reduces DAG and inflammatory signaling (29), while the inverse is observed in mice in which AMPK is impaired (2).

In obese humans, adipose tissue AMPK activity is markedly downregulated, and this is associated with adipose tissue inflammation (30). Recent studies using the macrophage-like cell line RAW246.1 and RNAi or adenovirus expressing dominant negative and constitutively active AMPK $\alpha 1$ have demonstrated that AMPK activation prevents LPS- and fatty acid-induced production of inflammatory cytokines $(31,32)$. The mechanisms mediating these antiinflammatory effects are still unclear, but AMPK activation of the Akt/PKB (Akt) and glycogen synthase kinase 3 pathway (31), the inhibition of ROS generation (33), MAPK signaling (33), and activation of sirtuin 1 (SIRT1) (32) have been 
A
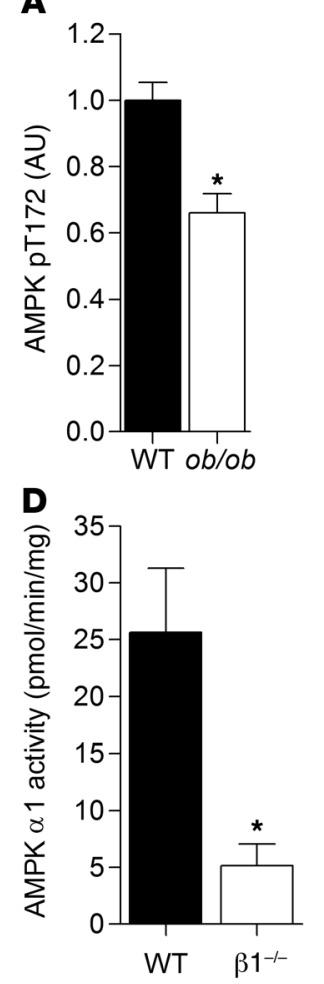

G

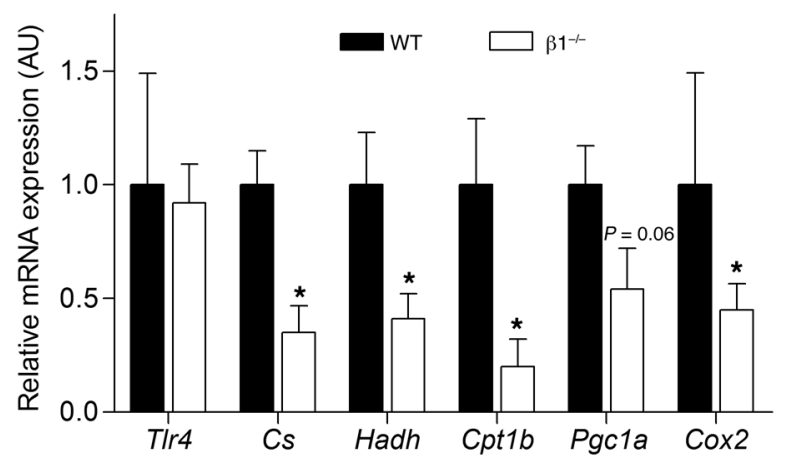

B

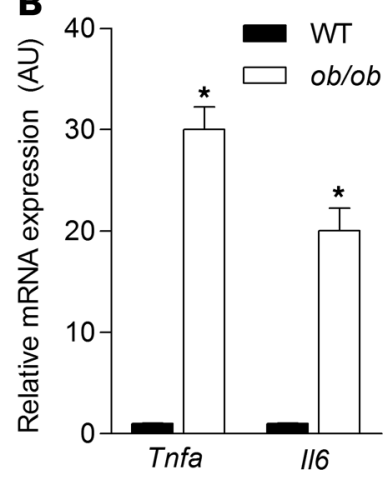

E
Tubulin

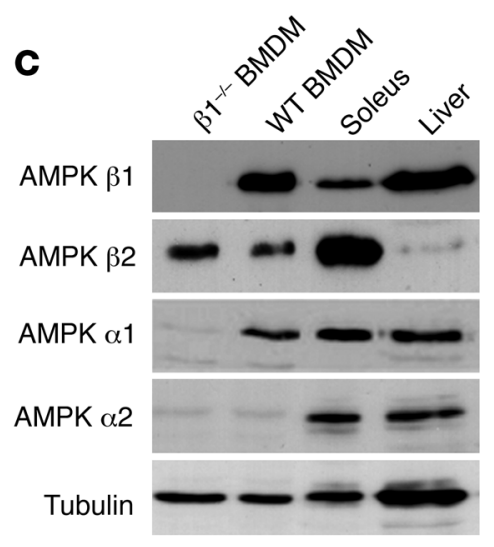

$\mathbf{F}$
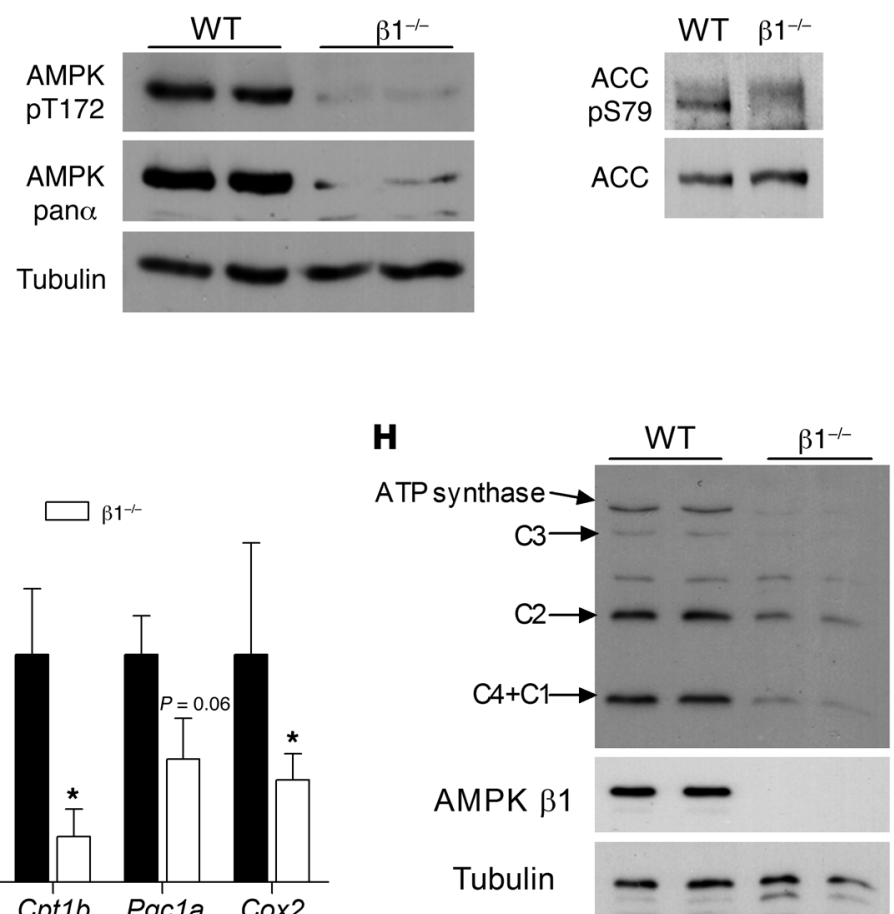

Figure 1

Deletion of AMPK $\beta 1$ from macrophages reduces AMPK $\alpha 1$ protein expression and activity and results in reductions in mitochondrial capacity. (A) Obese ob/ob mice have reduced AMPK activation, which is associated with increased expression of (B) Tnfa and II6. Cellular lysates from WT and $\beta 1^{-1-}$ BMDMs were subjected to (C) immunoblot analysis using AMPK $\alpha 1-, \alpha 2-, \beta 1-$, and $\beta 2-$ specific antibodies, (D) AMPK $\alpha 1$ activity assays, and (E) immunoblotting for AMPK pT172, AMPK pana, and (F) ACC S79 phosphorylation. (G) mRNA expression of TIr4 and mitochondrial markers (Cs, Hadh, Cpt1b, Pgc1a, and Cox2 [mitochondrial encoded]) in macrophages from $\beta 1^{-1-}$ and WT mice. (H) Cellular lysates from WT and $\beta 1^{-1-}$ BMDMs were subjected to immunoblot analysis for mitochondrial electron transport chain proteins. C1, complex I subunit $20 \mathrm{kDa}$; $\mathrm{C} 2$, complex II subunit $30 \mathrm{kDa}$; C3, complex III subunit core 2; C4, complex IV cytochrome oxidase-2. (Note: The unlabeled band is nonspecific, and $\mathrm{C} 4+\mathrm{C} 1$ appeared at approximately the same MW of $20 \mathrm{kDa}$.) Data are expressed as mean $\pm \mathrm{SEM} ; n=6-8$. ${ }^{*} P<0.05 \mathrm{compared}$ with $\mathrm{WT}$, where gene expression was normalized to $18 \mathrm{~s}$.

proposed. Despite the potential importance of macrophage AMPK in regulating inflammatory signaling and lipid metabolism, its role in controlling obesity-related inflammation has not been examined in vivo. In the current study, we provide the first evidence to our knowledge that genetic deletion of the AMPK $\beta 1$ subunit drastically reduces macrophage AMPK $\alpha 1$ activity, suppressing the expression of mitochondrial enzymes and ACC phosphorylation, which results in increased macrophage lipid accumulation and inflammation. Adoptive transfer of $\beta 1^{-/-}$bone marrow into WT recipient mice resulted in M1 activation of adipose tissue macrophages, leading to systemic inflammation and the development of whole-body hyperinsulinemia and hyperglycemia due to both hepatic and adipose tissue insulin resistance. These studies demonstrate that hematopoietic AMPK is a critical regulator of obesity-induced inflammation and whole-body glucose homeostasis. 

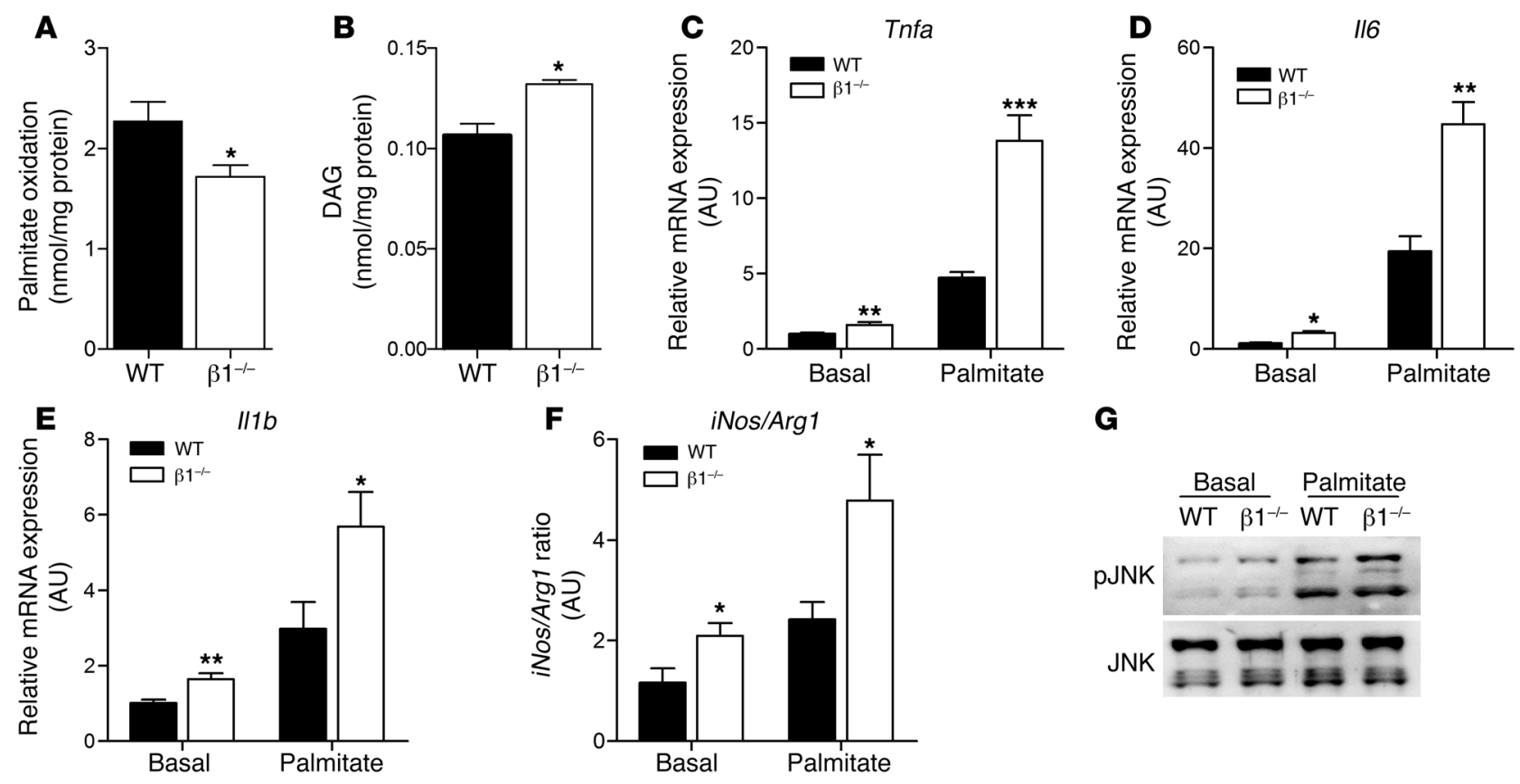

G
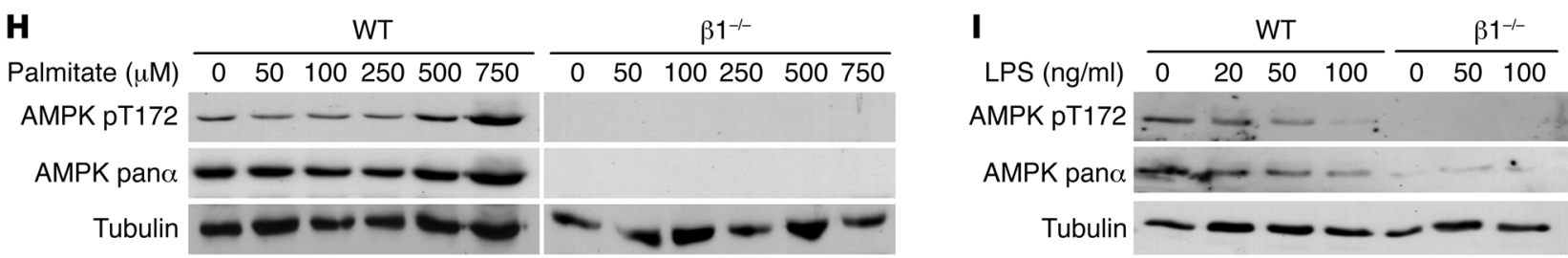

Figure 2

AMPK $\beta 1$ buffers against lipid accumulation and palmitate-induced macrophage inflammation. WT and $\beta 1^{-/-}$BMDMs were incubated with palmitate $\left(0.5 \mathrm{mM}, 0.5 \mu \mathrm{Ci} / \mathrm{ml}{ }^{14} \mathrm{C}\right.$-palmitate) for 4 hours and $(\mathbf{A})$ fatty acid oxidation and (B) DAG esterification measured. To investigate the state of macrophage polarization, we incubated WT and $\beta 1^{-/}$BMDMs with or without palmitate $(0.5 \mathrm{mM})$ for 24 hours and determined the gene expression of (C) Tnfa, (D) //6, and (E) $/ / 1 b$ and (F) the ratio of iNos to Arg1 gene expression as a marker of M1/M2 activation. (G) Cells were treated with or without palmitate $(0.5 \mathrm{mM})$ for 4 hours, and phosphorylation of JNK (Thr183/Tyr185) was assessed. (H) WT and $\beta 1^{-/-}$BMDMs were treated with palmitate at the indicated concentrations for 3 hours and cellular lysates probed with antibodies specific for phosphorylated AMPK T172, total AMPK $\alpha$ protein, and tubulin. (I) WT and $\beta 1^{-1-}$ BMDMs were incubated with increasing concentrations of LPS, and pT172, total AMPK $\alpha$ protein, and tubulin protein expression was determined. Data are expressed as mean $\pm \mathrm{SEM} ; n=3$, from at least 2 independent experiments. ${ }^{\star} P<0.05,{ }^{\star \star} P<0.01,{ }^{\star \star \star} P<0.001$ compared with $\mathrm{WT}$, where gene expression was normalized to Actb.

\section{Results}

Obese mice have reduced macrophage AMPK T172 phosphorylation. To address whether macrophage AMPK may be important in obesityrelated inflammation, we obtained peritoneal derived cells from lean and obese $o b / o b$ mice and used FACS to identify cells that were positive for the macrophage markers F4/80 and CD11b. From this macrophage population, we then measured activating phosphorylation of AMPK using an Alexa Fluor 488-labeled AMPK $\alpha$ T172 antibody. We found that AMPK T172 phosphorylation was reduced by approximately $33 \%$ in macrophages from $o b / o b$ mice, and this was associated with a marked increase in macrophage inflammation (Figure 1, A and B).

Deletion of AMPK $\beta 1$ reduces macrophage AMPK activity and reduces mitochondrial content. AMPK activity is dependent on the expression of an AMPK $\alpha \beta \gamma$ heterotrimer in which multiple isoforms of each subunit exist $(\alpha 1, \alpha 2, \beta 1, \beta 2, \gamma 1, \gamma 2, \gamma 3)$. Bone marrow-derived macrophages (BMDMs) exclusively expressed AMPK $\alpha 1$ and had no detectable $\alpha 2$ protein expression (Figure 1C) or activity (data not shown). AMPK $\alpha 1$ activity and expression were predominately dependent on binding to the $\beta 1$ subunit, as deletion of $\beta 1$ resulted in a greater than $85 \%$ reduction in AMPK activity and barely detectable AMPK T172 phosphorylation (Figure 1, D and E).

AMPK is an important regulator of fatty acid oxidation, an effects mediated through phosphorylation of its downstream substrate ACC. We found that macrophages exclusively express ACC1, in contrast to hepatocytes, which express both ACC1 and ACC2 isoforms (Supplemental Figure 1; supplemental material available online with this article; doi:10.1172/JCI58577DS1) and that consistent with reductions in AMPK activity, the phosphorylation of ACC1 was dramatically reduced in $\beta 1^{-/-}$macrophages (Figure $1 \mathrm{~F}$ ). AMPK is also an important regulator of mitochondrial biogenesis. Macrophages from $\beta 1^{-/-}$mice had no change in the expression of the innate immune receptor Tlr4, but had a greater than $50 \%$ reduction in mRNA expression of the mitochondrial encoded Cox2 (Figure 1G). This reduction in mRNA content corresponded to an approximately $50 \%$ reduction in protein expression of mitochondrial electron transport chain proteins in macrophages from $\beta 1^{-/-}$mice relative to WT littermates (Figure $1 \mathrm{H}$ ). These data dem- 
A

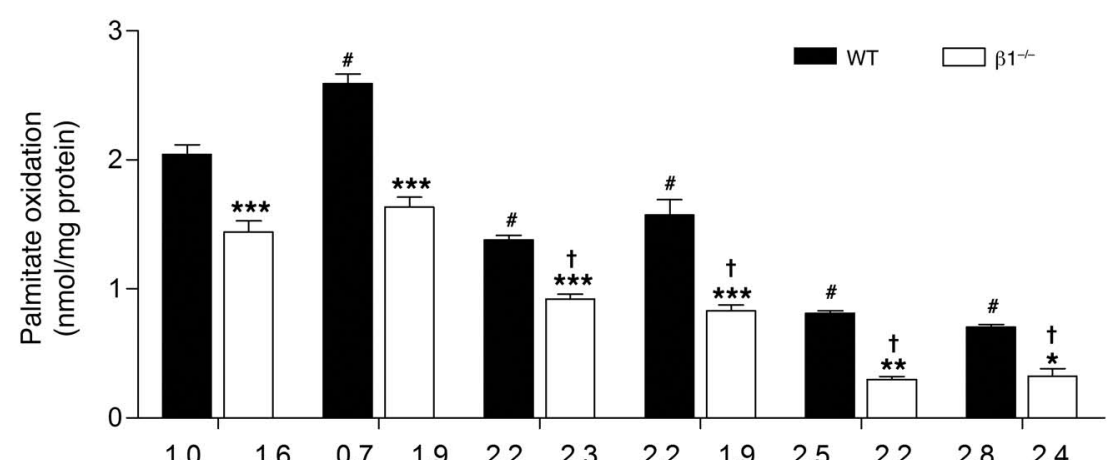

B

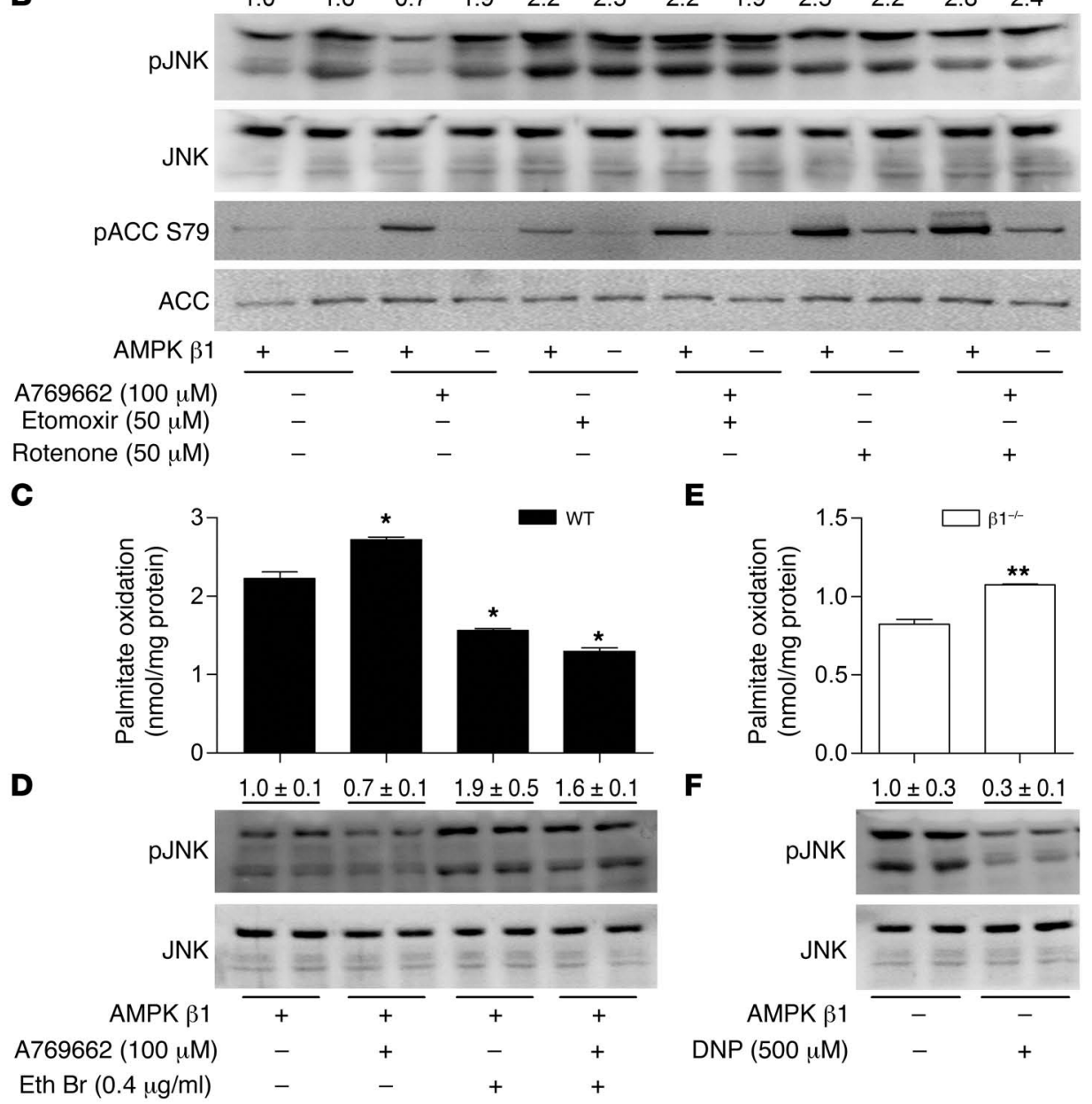

\section{Figure 3}

Mitochondrial fatty acid oxidation and $\beta 1$-specific activation of AMPK suppresses JNK phosphorylation in WT but not $\beta 1^{-1-}$ macrophages. (A) WT and $\beta 1^{-/-}$BMDMs were treated with $0.5 \mathrm{mM}$ palmitate $\left(0.5 \mu \mathrm{Ci} / \mathrm{ml}{ }^{14} \mathrm{C}\right.$-palmitate $)$ for 4 hours in the presence of $A 769662$ $(100 \mu \mathrm{M})$, etomoxir $(50 \mu \mathrm{M})$, and/or rotenone $(50 \mu \mathrm{M})$ before determination of fatty acid oxidation. (B) BMDMs were incubated as described above with $0.5 \mathrm{mM}$ palmitate and immunoblotted for $p$-JNK/JNK (T183/Y185) and p-ACC (S79)/ACC as a measure of AMPK activation. Treatment of WT BMDMs with ethidium bromide (Eth $\mathrm{Br})(0.4 \mu \mathrm{g} / \mathrm{ml})$ in the presence or absence of A769662 $(100 \mu \mathrm{M})(\mathbf{C})$ reduces fatty acid oxidation and increases (D) JNK phosphorylation, blocking the effects of A769662. $\beta 1^{-/}$BMDMs were treated with or without dinitrophenol (DNP) $(500 \mu \mathrm{M})$, and (E) fatty acid oxidation and (F) p-JNK/JNK levels were determined. Data are expressed as mean \pm SEM; $n=3-5$ from at least 2 independent experiments. ${ }^{*} P<0.05$, ${ }^{\star \star} P<0.01,{ }^{\star \star \star} P<0.001$ compared with WT; $\# P<0.05$ compared with WT basal; and ${ }^{\dagger} P<0.05$ compared with $\beta 1^{-/-}$basal. For expression of total JNK, duplicate gels were used. onstrate that the deletion of AMPK $\beta 1$ reduces macrophage AMPK activity, ACC phosphorylation, and mitochondrial content.

AMPK $\beta 1$-deficient macrophages are M1 activated and display increased sensitivity to saturated fatty acids. Reduced ACC phosphorylation and mitochondrial content in $\beta 1^{-/-}$macrophages was associated with reduced rates of fatty acid oxidation $(27 \%, P<0.05)$ (Figure $2 \mathrm{~A}$ ) and increased DAG esterification compared with cells from WT mice (Figure 2B). Ceramide levels were not different between genotypes (data not shown). Since DAG activates inflammatory pathways (34), we subsequently examined markers of macrophage polarization and found that $\beta 1^{-/-}$BMDMs had higher expression of inflammatory cytokines Tnfa, Il6, and $I l 1 b$, a difference that was exacerbated by the addition of palmitate (Figure 2, C-E). Great- er classical activation of $\beta 1^{-/-}$BMDMs was also evident, as there was an increase in the iNos to arginase-1 (Arg1) expression ratio (Figure 2F). Consistent with these changes in gene expression, we found that JNK phosphorylation was increased in $\beta 1^{-/-}$BMDMs, an effect that became greater following palmitate treatment (Figure $2 \mathrm{G}$ ). Importantly, these changes in JNK phosphorylation and mRNA transcripts, suggestive of increased M1 activation, were also reflected by alterations in cytokine secretion; as $\beta 1^{-/-}$BMDMs had a $56 \%$ reduction in the antiinflammatory cytokine IL-10 and $46 \%$ and $61 \%$ increases in TNF- $\alpha$ and IL-6, respectively (Supplemental Table 1). These inflammatory effects were not specific to palmitate, as similar observations were also made with the saturated fatty acid stearate (Supplemental Figure 2). 
A

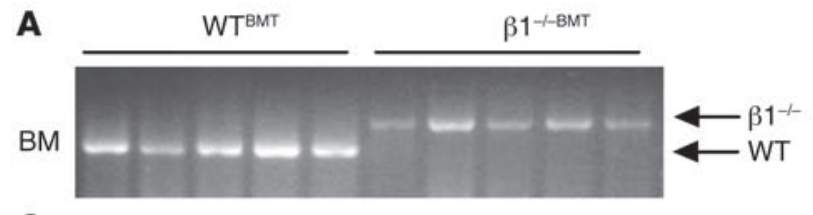

C
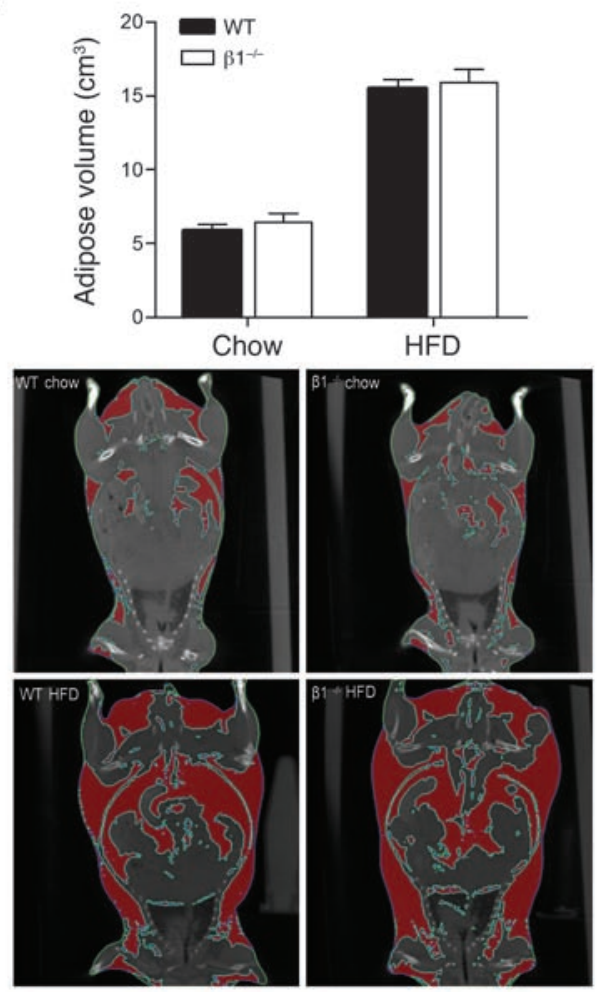
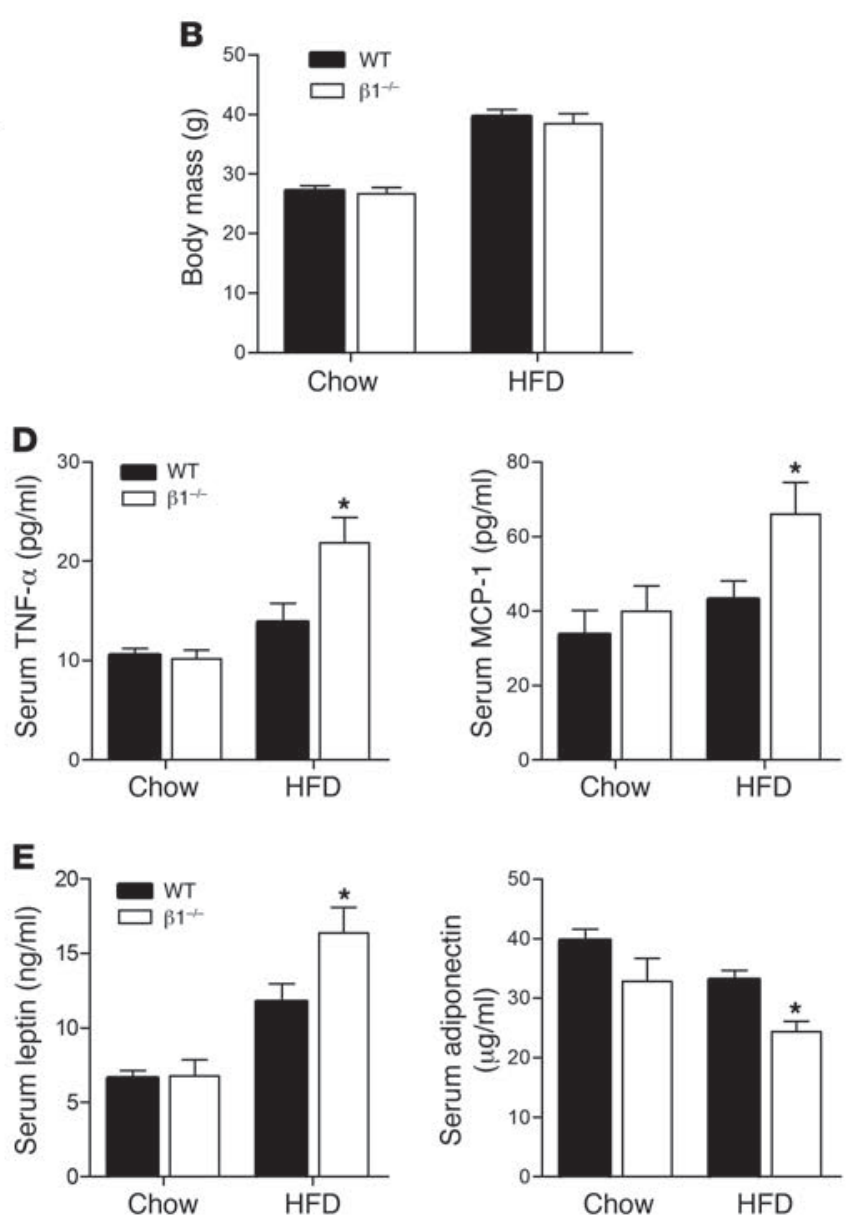

Figure 4

Hematopoietic deletion of AMPK $\beta 1$ results in systemic inflammation despite similar body mass and adiposity. WTBMT and $\beta 1^{-/-B M T}$ mice were fed chow or HFD for 22 weeks. (A) PCR analysis of genomic DNA isolated from bone marrow, using WT or $\beta 1^{-/}$specific primers. (B) Body weight and (C) total adiposity as determined by CT (with representative captures shown). (D) Serum MCP-1 and TNF- $\alpha$ and (E) serum leptin and adiponectin levels in chow- and HFD-fed mice. Data are expressed as mean $\pm \mathrm{SEM} ; n=8-10 .{ }^{*} P<0.05$ compared with WTBMT.

To examine whether AMPK $\beta 1$ deficiency altered sensitivity to other M1 or M2 stimulants, we incubated cells with LPS and IL-4, respectively. In contrast to the effects of saturated fatty acids, both LPS and IL-4 exerted effects on inflammatory markers, largely independent of AMPK $\beta 1$ deficiency (Supplemental Figure 3, $A$ and $B)$. To investigate the reason for the differential response between the M1 stimulants palmitate and LPS, we examined their effects on AMPK expression and activity and found that similar to our previous findings in muscle (35), palmitate concentrations that induce macrophage inflammation acutely activated AMPK in WT but not $\beta 1^{-/-}$macrophages, without altering AMPK $\alpha$ expression (Figure $2 \mathrm{H})$. In contrast, but in agreement with previous reports $(31,32)$, LPS was found to suppress AMPK activity largely due to a reduction in AMPK $\alpha$ expression (Figure 2I). These data suggest that "feed-forward" activation of AMPK resulting in increases in fatty acid oxidation is important for buffering against palmitate-induced inflammation, but in obesity, increases in LPS (36) and subsequent degradation of AMPK $\alpha$ likely contribute to the observed decrease in macrophage AMPK activity.

AMPK $\beta 1$ regulation of fatty acid oxidation is essential for inhibiting lipidinduced macrophage inflammation. To address the hypothesis that acti- vation of fatty acid oxidation was central to buffering against lipidinduced inflammation, we performed a series of experiments in WT and $\beta 1^{-/-}$macrophages in which we pharmacologically activated AMPK using the small molecule, $\beta 1$-specific activator A769662 (37, 38), while inhibiting fatty acid oxidation using inhibitors of either CPT-1 (etomoxir) or mitochondrial complex-1 (rotenone). Following the various treatments, the activating phosphorylation of JNK was used as an assay to assess macrophage inflammation (7), while the phosphorylation of ACC was used as a surrogate measure of AMPK activity (38). We found that $\mathrm{A} 769662$ selectively and dose-dependently increased ACC phosphorylation in WT but not $\beta 1^{-/-}$BMDMs (Supplemental Figure 4A). The activation of $\beta 1$ resulted in a significant increase in fatty acid oxidation (Figure 3A) and, importantly, reduced JNK activation (Figure 3B) in WT but not $\beta 1^{-/-}$cells. Both etomoxir and rotenone decreased rates of fatty acid oxidation (Figure 3A) and subsequently increased JNK phosphorylation (Figure 3B), but importantly, this affect could not be reversed, despite activation of AMPK.

Interestingly, basal differences in fatty acid oxidation between genotypes were preserved in the presence of etomoxir and rotenone, suggesting that the primary cause of the reduced fatty acid oxidation in $\beta 1^{-/}$BMDMs was due to a lower mitochondrial content 

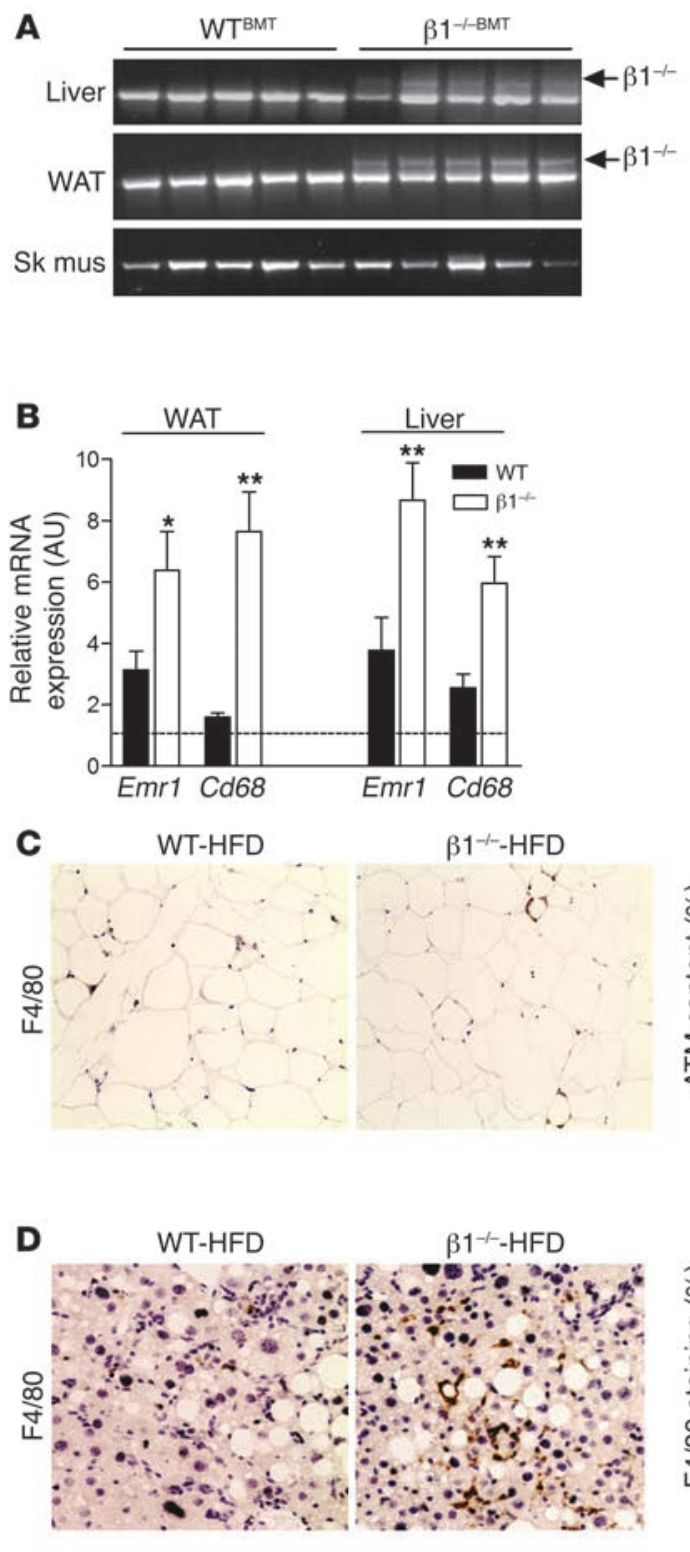
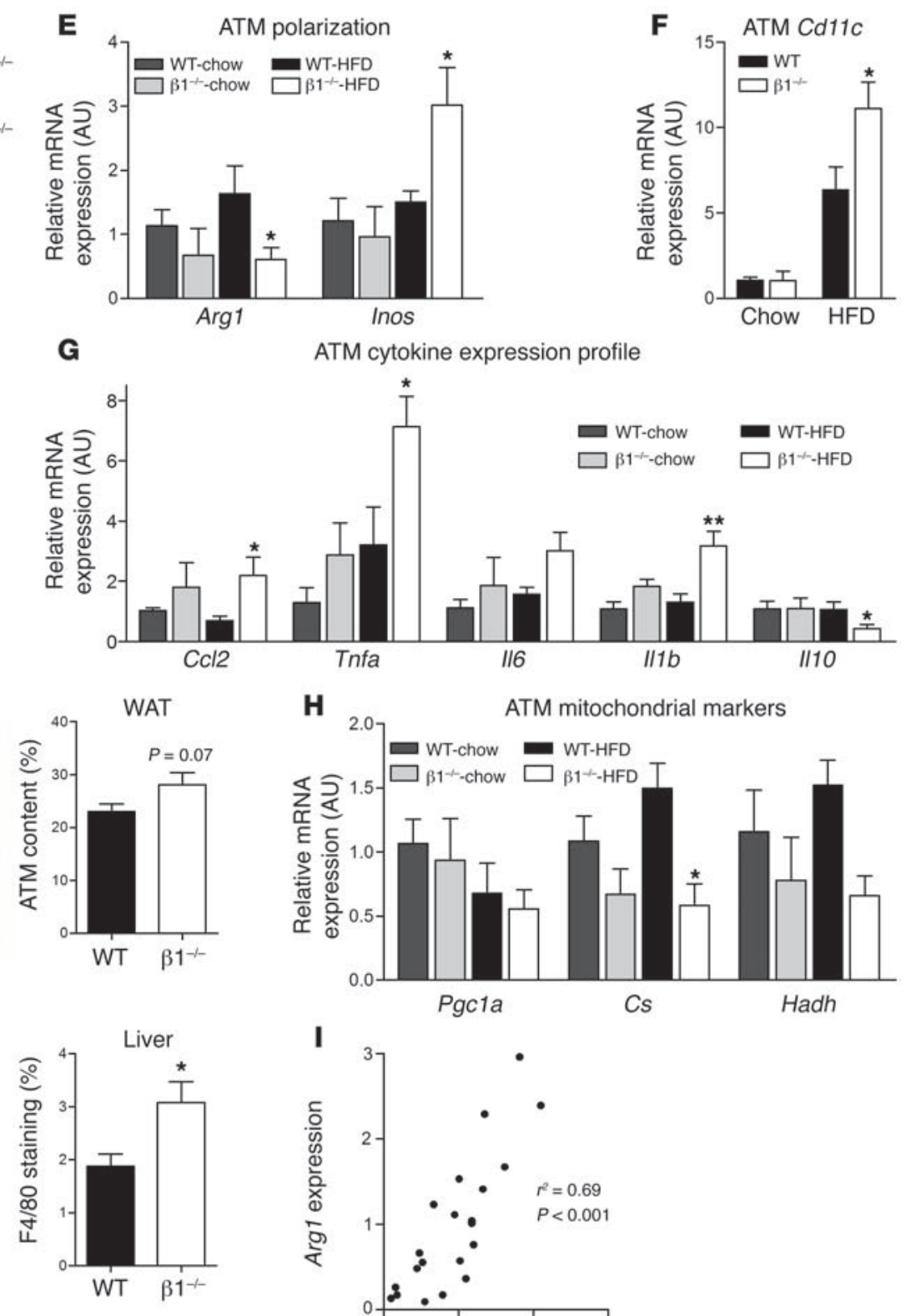

Figure 5

Hematopoietic deletion of AMPK $\beta 1$ results in macrophage recruitment and inflammatory activation of adipose tissue macrophages. (A) PCR genotyping of genomic DNA from liver, white adipose tissue (WAT), and skeletal muscle (Sk mus), with WT- or $\beta 1$-specific primers. (B) mRNA expression of macrophage markers Emr1 (F4/80) and Cd68 in WAT and liver of HFD-fed WTBMT and $\beta 1^{-1-B M T}$ mice (dotted line indicates expression in chow-fed WTBMT mice). Immunohistochemical staining and quantification of F4/80 in (C) WAT and (D) liver (original magnification, $\times 200$ ). Adipose tissue macrophage (ATM) mRNA expression of (E) Arg1 and iNos, (F) Itgax (Cd11C), (G) inflammatory cytokines Cc/2, Tnfa, II6, II1 b, and I/10, and (H) markers of mitochondrial density Pgc1a, Cs, and Hadh. (I) Correlation analysis between expression of Cs and Arg1. All data presented are mean \pm SEM; $n=8-10 .{ }^{*} P<0.05,{ }^{\star \star} P<0.01$ compared with WTBMT, within dietary treatment, where the relative expression was normalized to Actb.

and not an increase in malonyl-CoA inhibition of CPT-1. Therefore, we also depleted mitochondrial DNA from WT macrophages using ethidium bromide. In agreement with previous reports (39, 40), ethidium bromide treatment inhibited mitochondrial (Cox2) but not nuclear encoded DNA (Cs, Bhad) (Supplemental Figure 4B), reducing the expression of complex I, complex II, and complex IV by approximately $40 \%$ (Supplemental Figure 4C). Consistent with findings from $\beta 1^{-/-}$macrophages, we found that lower levels of mitochondria led to reductions in fatty acid oxidation (Figure 3C) and dramatically increased the phosphorylation of JNK (Figure 3D). Treatment of mitochondrial depleted macrophages with A769662 had no effect on fatty acid oxidation and was unable to prevent palmitate-induced JNK phosphorylation (Figure 3, $\mathrm{C}$ and $\mathrm{D}$ ). Last, we attempted to rescue the inflamed phenotype 

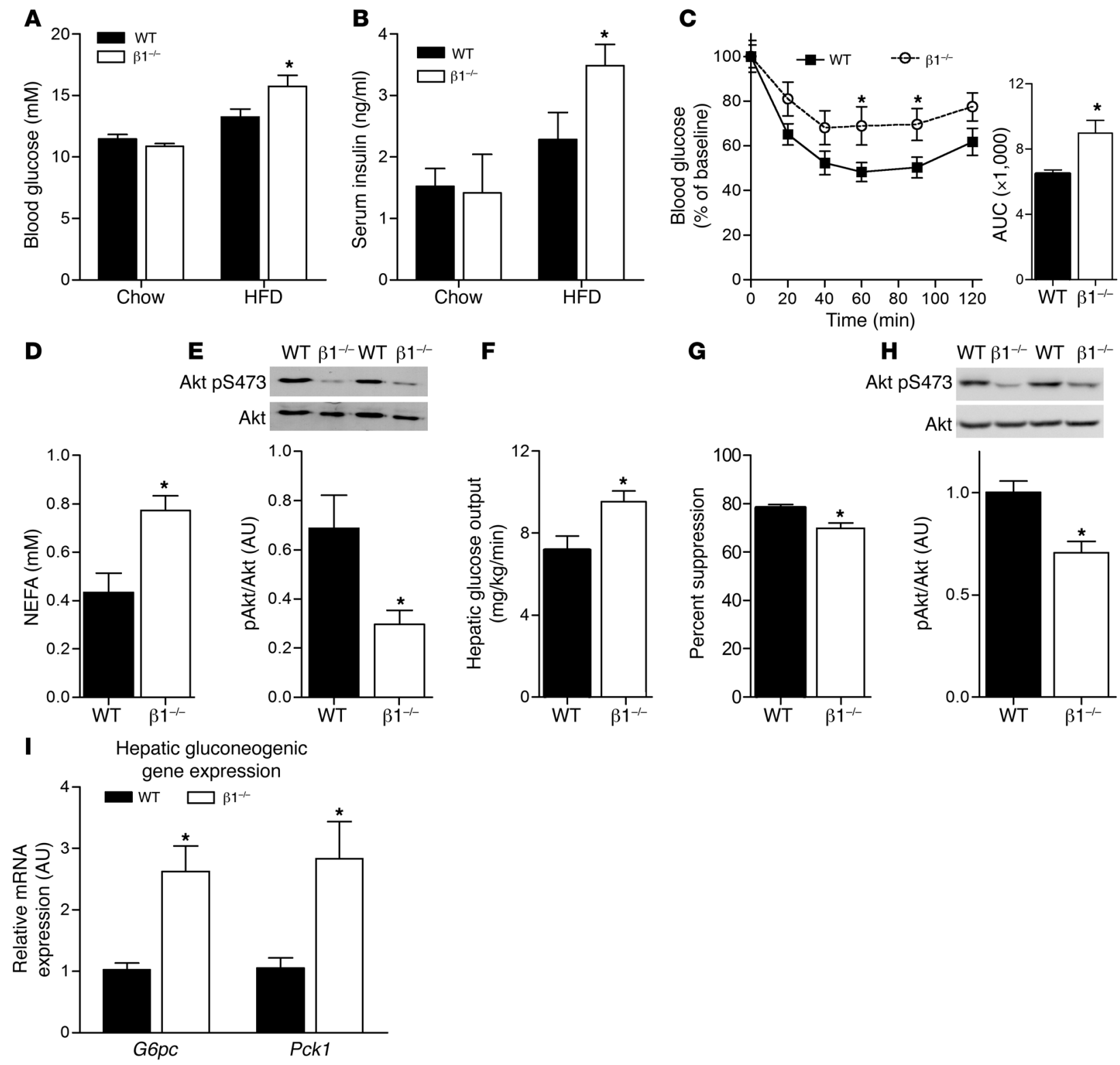

$\mathbf{F}$

G

H $\quad W T \beta 1^{--} W T \beta 1^{--}$
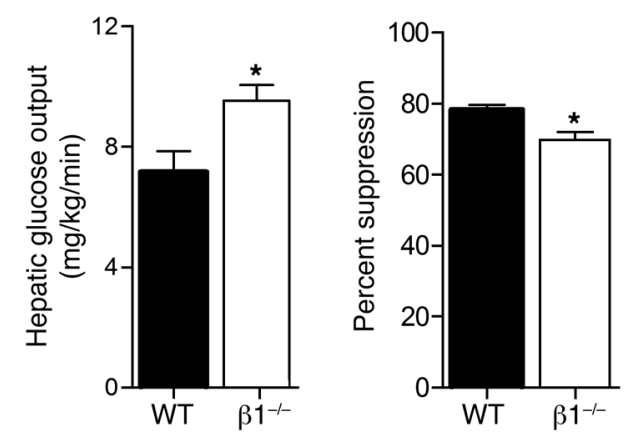

Akt pS473

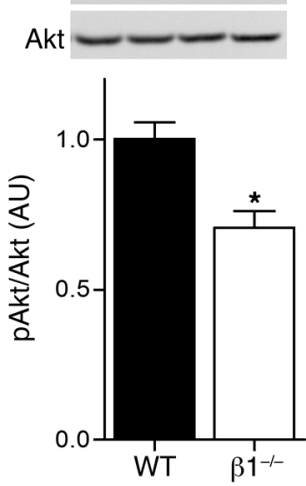

\section{Figure 6}

Hematopoietic deletion of AMPK $\beta 1$ causes adipose tissue and hepatic insulin resistance. WTBMT and $\beta 1^{-/-B M T}$ mice were fed a chow diet or HFD for 22 weeks, and (A) fed blood glucose and (B) serum insulin levels were determined. (C) WTBMT and $\beta 1^{-/-B M T}$ mice fed HFD were fasted for 6 hours and insulin tolerance tests performed after intraperitoneal injection of $0.7 \mathrm{U} / \mathrm{kg}$ insulin (right: AUC calculated as $\mathrm{mM}{ }^{*} \mathrm{~min}$ ). Hyperinsulinemic-euglycemic clamps were performed in WTBMT and $\beta 1^{-/-B M T}$ fed HFD, and (D) post-clamp serum NEFA and (E) adipose tissue Akt (pS473) phosphorylation were determined. (F) Hepatic glucose output and (G) percent suppression of hepatic glucose production were measured, and livers were collected after the clamp for analysis of (H) phosphorylated Akt (S473) and (I) mRNA expression of gluconeogenic enzymes G6pc and Pck1. All data presented are mean \pm SEM; $n=8-10 .{ }^{*} P<0.05$ compared with WTBMT within dietary treatment, where relative expression was normalized to Actb. For expression of total Akt, duplicate gels were used.

of $\beta 1^{-/-}$macrophages by increasing fatty acid oxidation using the mitochondrial uncoupler dinitrophenol and found that increased rates of fatty acid oxidation (Figure $3 \mathrm{E}$ ) led to marked reductions in JNK phosphorylation (Figure 3F). Taken together, these data demonstrate that AMPK $\beta 1$ is required to prevent lipid-induced inflammation through the activation of fatty acid oxidation.

Hematopoietic deletion of AMPK $\beta 1$ results in systemic inflammation despite similar body mass and adiposity. To assess the role of AMPK in regulating obesity-induced inflammation and the potential impact on obesity-related insulin resistance in vivo, we generated WT (WT ${ }^{\mathrm{BMT}}$ ) and $\beta 1^{-/-}\left(\beta 1^{-/-\mathrm{BMT}}\right)$ chimeras by transplanting bone marrow from $\beta 1^{-/}$and WT littermates into lethally irradiated WT recipients. After a 6-week recovery period, mice were either maintained on a chow diet or switched to a diet high in fat for 22 weeks. We confirmed the efficiency of the engraftment of WT and $\beta 1^{-/-}$bone marrow by measuring WT and $\beta 1^{-/-}$PCR products in bone marrow of WT recipients (Figure 4A). Recent studies have shown that LKB1 but not AMPK is important for regulating 
A
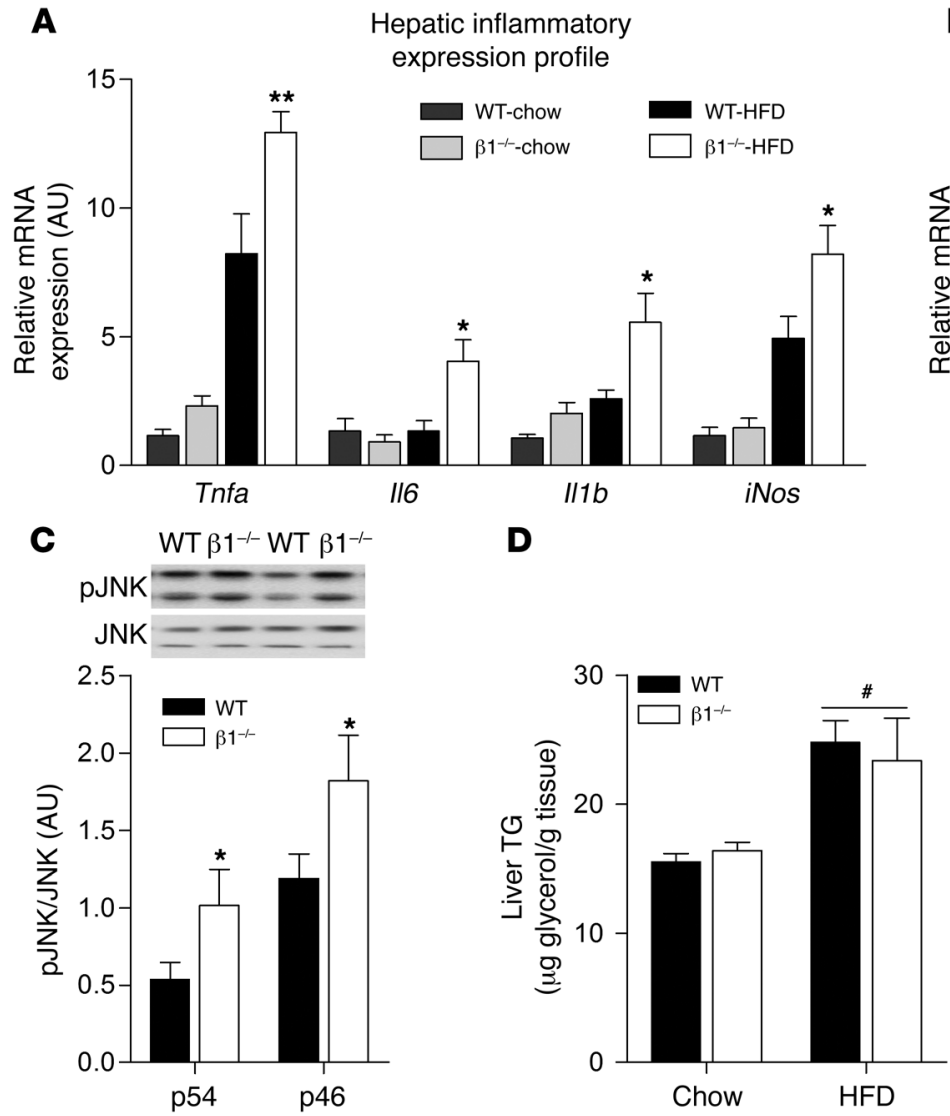

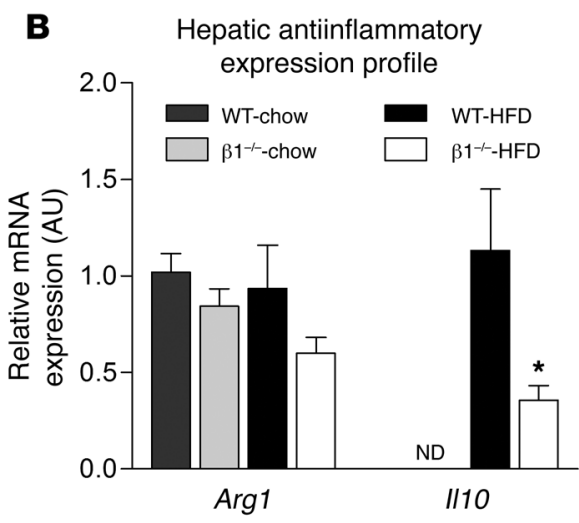

$\mathbf{E}$

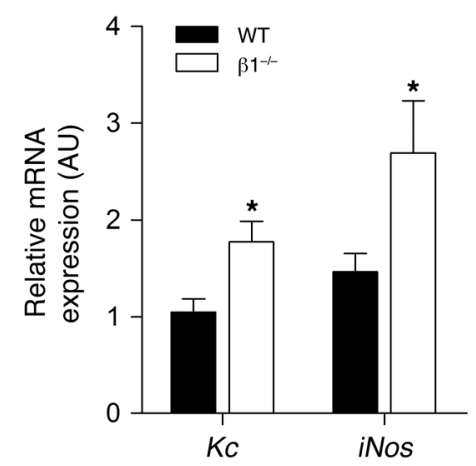

F Hepatocyte insulin resistance with macrophage conditioned medium

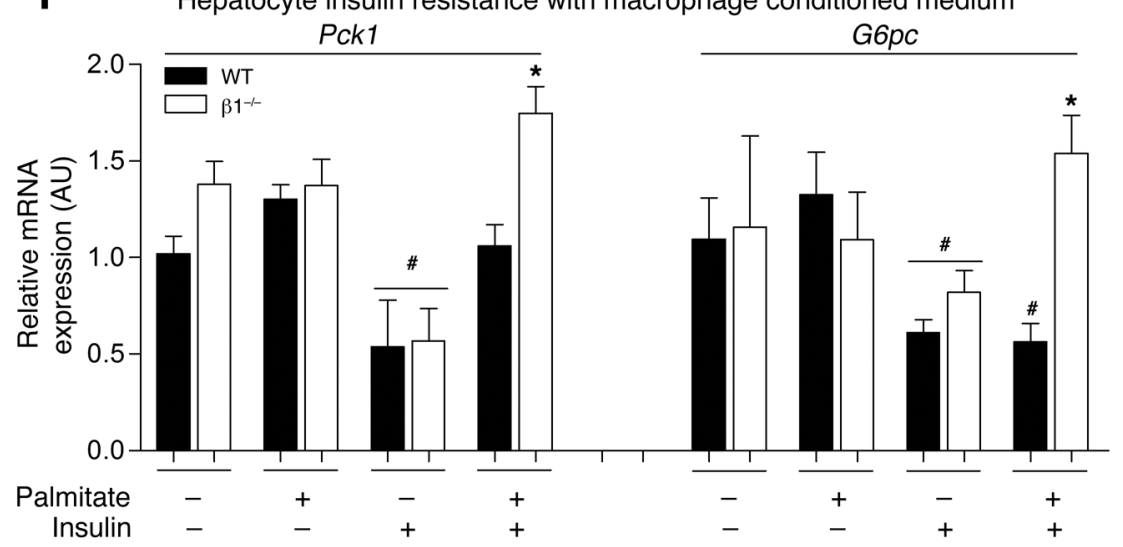

Figure 7

Increased hepatic inflammation due to $\beta 1$ deletion in macrophages leads to hepatic insulin resistance. (A) mRNA expression inflammatory cytokine production in liver tissue from WTBMT and $\beta 1^{-/-B M T}$ mice on chow and HFD: //1b, Tnfa, I/6, and iNos. (B) Antiinflammatory marker expression in WTBMT and $\beta 1^{-/-B M T}$ livers: Arg1 and I/10. (C) Immunoblotting for phosphorylated JNK (T183/Y185) and total JNK between genotypes fed HFD. (D) Liver triglyceride (TG) levels in WTBMT and $\beta 1^{-/-B M T}$ mice fed chow or HFD. Primary hepatocytes were incubated with conditioned medium from $0.5 \mathrm{mM}$ palmitate-treated WT and $\beta 1^{-/}$BMDMs for 4 hours (as described in Methods). (E) The mRNA expression of markers of hepatocyte inflammation $K c$ and $i N o s$ and $(F)$ the mRNA expression of gluconeogenic genes following 4 hours treatment with $10 \mathrm{nM}$ insulin. All data shown are mean \pm SEM; $n=8-10$ for animal experiments. In vitro work was performed in triplicate from at least 2 livers. ${ }^{*} P<0.05$, ${ }^{* *} P<0.01$ compared with WT, within treatment group; ${ }^{\sharp} P<0.05$ between basal and insulin treatment within genotype, where expression was normalized to Actb. For expression of total JNK, duplicate gels were used. ND, not detected.

hematopoietic cell growth and proliferation (41-43). Consistent with these reports, there were no differences in $\mathrm{T}$ cell, $\mathrm{B}$ cell, or macrophage numbers in the bone marrow, spleen, or thymus of WT and $\beta 1^{-/-}$mice (data not shown). Since the activation of T cells has been shown to play an important role in regulating obesityinduced inflammation and insulin sensitivity (44-46), we also measured markers of $\mathrm{T}$ cell activation. There were no differences in the percentage of $\mathrm{CD}^{+} / \mathrm{CD}^{+}$cells or in Foxp 3 expression between 
genotypes, and while the HFD increased T cell infiltration into adipose tissue and liver, there was no difference between genotypes (Supplemental Figure 5, A-D).

We found that on the control chow diet, there was no difference in body mass (Figure 4B) or adiposity (Figure 4C) between WT BMT $^{\text {BMT }}$ and $\beta 1^{-/ \text {-BMT }}$ mice, and while the HFD increased both body mass and adiposity, there were no discernible differences between genotypes. There were no detectable differences in serum cytokines in chow-fed mice. However, despite similar body mass and adiposity, levels of serum monocyte chemoattractant protein-1 (MCP-1) and TNF- $\alpha$ were higher in HFD-fed $\beta 1^{-/ \text {BMT }}$ mice (Figure 4D). Consistent with known effects of TNF- $\alpha$ on the adipokines leptin $(47,48)$ and adiponectin (49), we found that HFD-fed $\beta 1^{-/-B M T}$ mice had increased leptin and reduced adiponectin levels (Figure 4E). Systemic inflammation leads to hypothalamic leptin resistance (50-52), and consistent with the increase in circulating TNF- $\alpha$, we found that HFD-fed $\beta 1^{-/-\mathrm{BMT}}$ mice had increased food intake and hypothalamic expression of the orexigenic peptide Npy (Supplemental Figure 6, A and B). However, increases in energy intake of HFD-fed $\beta 1^{-/ \text {BMT }}$ mice appeared to be offset by a corresponding increase in activity levels, particularly at the onset of feeding (Supplemental Figure 6C).

Hematopoietic deletion of AMPK $\beta 1$ results in the infiltration of liver and adipose tissue with macrophages. In obesity, BMDMs accumulate within white adipose tissue and liver (Kupffer cells). We detected substantial infiltration of $\beta 1^{-/-}$bone marrow-derived cells into liver and white adipose tissue, but not skeletal muscle, of $\beta 1^{-/ \text {-BMT }}$ mice (Figure 5A). We subsequently examined the macrophage content of liver and white adipose tissue using quantitative RT-PCR (qRTPCR) (Emr1 [F4/80] and Cd68) or histological staining (F4/80). On the control chow diet, there were modest increases in $\mathrm{Cd} 68$ but not Emr1 expression in the adipose tissue and liver (Supplemental Figure $7, \mathrm{~A}$ and $\mathrm{B})$. However, when fed HFD, $\beta 1^{-/ \mathrm{BMT}}$ mice had greater expression of Emr1 and Cd68 in both adipose tissue and liver (Figure 5B). Consistent with the increase in mRNA transcripts, immunohistochemical staining of $\mathrm{F} 4 / 80$ was greater in adipose tissue (Figure 5C) and liver (Figure 5D) of HFD-fed $\beta 1^{-/ \text {-BMT }}$ mice, indicating increased macrophage infiltration.

Hematopoietic deletion of AMPK $\beta 1$ results in the inflamed adipose tissue macrophages. We subsequently examined the inflammatory profile of adipose tissue macrophages and found that adipose tissue macrophages from HFD-fed $\beta 1^{-/ \text {-BMT }}$ mice had lower expression of Arg1 and increased $i$ Nos (Figure 5E) and Itgax (Cd11c) expression (Figure $5 \mathrm{~F}$ ), indicating that the deletion of AMPK $\beta 1$ promoted macrophage M1 activation. Consistent with this activation state, adipose tissue macrophages from $\beta 1^{-/ \text {BMT }}$ mice on a chow diet tended to have increased inflammatory cytokine expression ( Tnfa, $I l 6, C c l 2, I l 1 b)$ and lower expression levels of antiinflammatory Il10, a difference that became much more dramatic when mice were fed HFD (Figure 5G). We also observed that increases in inflammation were associated with reduced expression of mitochondrial markers such as $\mathrm{Cs}$ and Hadh (Figure 5, H and I), a finding consistent with our observations in vitro. These data demonstrate that deletion of AMPK $\beta 1$ from macrophages results in a shift toward inflammatory, M1-activated adipose tissue macrophages.

Hematopoietic deletion of $A M P K \beta 1$ results in hepatic insulin resistance. We next examined glucose homeostasis and insulin sensitivity and found that on the control chow diet, overnight fasted (data not shown) and fed glucose (Figure 6A) and insulin levels (Figure 6B) were not different between WT ${ }^{\mathrm{BMT}}$ and $\beta 1^{-/ \text {BMT }}$ mice. When challenged with HFD, $\beta 1^{-/-B M T}$ mice had significantly elevated serum glucose and insulin levels (Figure 6, A and B). Consistent with the insulin and glucose levels, we found that chow-fed $\beta 1^{-/ \text {-BMT }}$ mice had normal insulin sensitivity following a bolus of insulin (Supplemental Figure 8 ), while $\beta 1^{-/ \text {-BMT }}$ mice fed HFD became refractory to the suppressive effects of insulin on blood glucose compared with $\mathrm{WT}^{\mathrm{BMT}}$ controls (Figure $6 \mathrm{C}$ ). To assess whether increased insulin resistance in HFD fed $\beta 1^{-/ \text {-BMT }}$ mice was due to peripheral or hepatic insulin resistance, we conducted hyperinsulinemiceuglycemic clamps. We did not clamp chow-fed mice, as there was no sign of insulin resistance. Blood glucose at the start of the clamp and basal glucose turnover were similar in WT $^{\mathrm{BMT}}$ and $\beta 1^{-/- \text {BMT }}$ mice (data not shown). Insulin-stimulated glucose disposal rate (data not shown) was not different between genotypes, despite higher levels of non-esterified fatty acids (NEFAs) and reduced Akt phosphorylation in adipose tissue, indicating the presence of adipose tissue insulin resistance (Figure 6, D and E). There was no difference in skeletal muscle Akt phosphorylation between HFDfed WT and $\beta 1^{-/-B M T}$ mice, suggesting that skeletal muscle did not develop insulin resistance (data not shown). HFD-fed $\beta 1^{-/-B M T}$ mice had increased hepatic glucose output (Figure 6F) and a blunted suppression of hepatic glucose production (Figure 6G), indicating hepatic insulin resistance. Consistent with this, we found that at the completion of the clamp, liver Akt phosphorylation was lower (Figure $6 \mathrm{H}$ ), while the expression of the gluconeogenic genes G6pc and Pck1 was elevated in $\beta 1^{-/-\mathrm{BMT}}$ mice (Figure 6I). Thus, $\beta 1^{-/ \text {-BMT }}$ mice developed exaggerated adipose tissue and liver insulin resistance compared with WT ${ }^{\mathrm{BMT}}$ mice when fed HFD.

Increased hepatic inflammation due to $\beta 1$ deletion in macrophages leads to hepatic insulin resistance. In agreement with the observed increase in macrophage infiltration into the liver of $\beta 1^{-/ \text {-BMT }}$ mice (Figure 5, A, B, and D), we found that there was also a marked increase in the expression of inflammatory cytokines Tnfa, Il6, Illb, and iNos and decreased expression of Arg1 and Il10 (Figure 7, A and B). This increase in inflammatory gene expression was accompanied by a $20 \%$ increase in liver IL- $1 \beta$ protein in HFD-fed $\beta 1^{-/ \text {BMT }}$ mice compared with $\mathrm{WT}^{\mathrm{BMT}}$ controls (Supplemental Table 2). Increased liver inflammation in HFD-fed $\beta 1^{-/- \text {BMT }}$ mice was associated with increased JNK phosphorylation (Figure 7C). Since inflammation could have been due to high levels of lipid, we measured liver triglycerides and found that while the HFD increased levels, there was no difference between $\mathrm{WT}^{\mathrm{BMT}}$ and $\beta 1^{-/ \text {BMT }}$ mice (Figure 7D). To determine whether the exacerbation of hepatic insulin resistance in $\beta 1^{-/ \text {-BMT }}$ mice could be attributed to increased inflammation in $\beta 1^{-/-}$macrophages, we treated WT primary hepatocytes with medium that had been conditioned from palmitate-treated WT and $\beta 1^{-/-}$BMDMs. We found that media from $\beta 1^{-/-}$BMDMs caused greater hepatic inflammation, as indicated by increased expression of Kc (a murine IL-8 homolog) and iNos (Figure 7E), and importantly, this was associated with an impaired ability of insulin to suppress Pck1 and G6pc expression in hepatocytes (Figure 7F). These findings, which paralleled those observed in vivo, support a critical role for macrophage AMPK $\beta 1$ in the regulation of liver inflammation and insulin sensitivity.

\section{Discussion}

Resident macrophages in lean adipose tissue are characterized by a program of gene expression that is directed toward limiting local inflammatory responses and promoting tissue repair. These alternative, or M2, macrophages are characterized by high levels of arginase and low levels of iNOS, which facilitates the production of collagen 
and secretion of antiinflammatory cytokines, such as IL-10 $(12,13)$. We detected lower levels of AMPK activity in inflamed macrophages from obese mice. Similarly, reducing AMPK activation through genetic deletion of the $\beta 1$ subunit resulted in lower levels of Arg1 and higher levels of $i N o s, I l 1 b$, and Tnfa, an M1 inflamed phenotype that was further exacerbated by treatment with palmitate. Importantly, we expand on these in vitro findings by showing that this M1-activated phenotype is also observed in vivo, in adipose tissue macrophages from obese $\beta 1^{-/ \text {-BMT }}$ mice. These findings demonstrate that even within the diverse metabolic milieu that defines the adipose tissue macrophage, AMPK activity is essential for regulating M1/M2 polarization. Notably, although no differences were observed in markers of $\mathrm{T}$ cell activation/infiltration, it remains possible that hematopoietic deletion of AMPK $\beta 1$ may have affected other cell lineages to influence the onset and severity of macrophage inflammation.

Our finding that $\beta 1$ deficiency resulted in a greatly enhanced inflammatory phenotype in response to palmitate or HFD challenge led us to the hypothesis that AMPK regulation of lipid metabolism may be important for controlling macrophage inflammation. We subsequently found that palmitate acutely increases AMPK activity and ACC phosphorylation in macrophages from WT mice and that deletion of $\beta 1$ reduces mitochondrial content and prevented phosphorylation of ACC. This resulted in reduced rates of fatty acid oxidation and increased accumulation of macrophage DAG. In agreement with recent findings showing a role for DAG in regulating macrophage inflammation (21), we show that $\beta 1^{-/-}$macrophages had much greater activation of JNK and increased expression and secretion of inflammatory cytokines both in vitro and in vivo. We subsequently established that the control of mitochondrial fatty acid oxidation is a critical factor for controlling inflammatory activation. Importantly, the activation of AMPK $\beta 1$-containing complexes in the absence of increases in fatty acid oxidation is unable to prevent lipid-induced inflammation. Since the activation of SIRT1 has been shown to require AMPK-dependent increases in fatty acid oxidation (28), our findings are consistent with recent reports showing that activation of AMPK inhibits inflammation via a SIRT1-dependent pathway (32) and that polarization of M1 macrophages in adipose tissue is associated with increased lipid accumulation (53). Taken together, these data demonstrate that pharmacological activation of AMPK $\beta 1$-containing complexes prevents lipid-induced inflammation and that the activation of fatty acid oxidation is required for this effect.

Consistent with the increased inflammation in HFD-fed $\beta 1^{-/- \text {BMT }}$ mice, we found that these mice developed more pronounced hyperglycemia and hyperinsulinemia than HFD-fed WT ${ }^{\text {BMT }}$ littermates. Subsequent studies using hyperinsulinemic-euglycemic clamps demonstrated the presence of both adipose tissue and hepatic insulin resistance. Given that the hematopoietic deletion of $\beta 1$ may have affected multiple cell types, including $T$ cells, that are important for regulating insulin sensitivity in obesity (44-46), we subsequently conducted conditioned medium experiments with BMDMs. We found that increased cytokine secretion from palmitate-treated $\beta 1^{-/-}$BMDMs induced greater hepatic inflammation and insulin resistance than medium from WT cells, thus supporting a critical role for macrophage AMPK $\beta 1$ in regulating hepatic insulin sensitivity. However, future studies are needed to investigate the role of AMPK $\beta 1$ in Kupffer cells.

We did not observe any differences in the glucose disposal rate in $\beta 1^{-/-\mathrm{BMT}}$ mice during the hyperinsulinemic-euglycemic clamp, despite evidence of adipose tissue insulin resistance, as demon- strated by higher levels of circulating NEFA and reduced adipose tissue Akt phosphorylation. These data suggest that skeletal muscle, which accounts for approximately $80 \%$ of glucose disposal during the clamp, did not develop insulin resistance. This may have been related to the lack of infiltration of bone marrowderived cells into this tissue and is consistent with other models of hematopoietic or myeloid specific disruptions in inflammatory signaling that failed to detect any changes in skeletal muscle insulin sensitivity $(11,16,17)$.

Loss of whole-body AMPK $\beta 1$ protects against HFD-induced obesity, liver lipid accumulation, and insulin resistance (54). This protection against obesity and insulin resistance was attributed to lower hypothalamic AMPK, which resulted in reduced food intake and hence body mass/adiposity (54). In contrast, we show that $\beta 1^{-/-B M T}$ mice develop greater HFD-induced hepatic insulin resistance than $\mathrm{WT}^{\mathrm{BMT}}$ controls. Since adipose tissue cell size appears to be the primary factor dictating macrophage recruitment and adipose tissue inflammation $(55,56)$ and mice lacking whole-body AMPK $\beta 1$ do not develop obesity, this may be a likely explanation for the disparity between mice with hematopoietic compared with global deletion of $\beta 1$.

In summary, our results demonstrate that macrophage AMPK $\beta 1$ is critical in regulating mitochondrial capacity and that the activation of fatty acid oxidation is essential for limiting inflammation in response to saturated fatty acids. We find that in lean mice, hematopoietic deletion of AMPK $\beta 1$ appears to have a relatively modest impact on adipose tissue macrophage inflammation. However, when mice are made obese and there is a dramatic need to buffer against lipids, AMPK is essential for controlling adipose tissue macrophage inflammation and in turn insulin sensitivity. Thus, macrophage AMPK may be the first line of defense to prevent the deleterious effects of nutrient overload during obesity. This raises the exciting possibility that the insulin-sensitizing effects of agents such as metformin, rosiglitazone, and exercise - all of which have been shown to reduce inflammation (14,57-59) and activate AMPK (60-65) - may be mediated in part by activation of AMPK in macrophages; however, to our knowledge, this has yet to be investigated. These studies also suggest that the recently developed thienopyridone class of AMPK $\beta 1$-specific activators, in addition to preventing insulin resistance $(37,38)$, may be effective in treating other inflammatory diseases such as atherosclerosis and rheumatoid arthritis.

\section{Methods}

Animals. All mice used in the study were males, housed in specific pathogen-free micro-isolators and maintained on a 12-hour light/12-hour dark cycle with lights on at 0700 . The generation and characterization of $\beta 1^{-/-}$ mice has been described previously $(54,66)$. For bone marrow transplantation experiments, whole bone marrow from WT and $\beta 1^{-/-}$mice was prepared by flushing the marrow cavities of the long bones with sterile saline. $5 \times 10^{6}$ cells were injected retro-orbitally into lethally irradiated (11 Gy) WT recipient mice (Animal Resources Centre). After a 6-week recovery period, mice were placed on a standard mouse chow diet $(12 \% \mathrm{kcal}$ fat, Barastoc, Ridley Agriproducts) or HFD (45\% kcal fat, diet SF-01-028, Specialty Feeds) for 22 weeks. Insulin tolerance tests were performed after 16 weeks of feeding as described previously (67). For serum insulin and cytokine measurements, fasting and fed blood samples were collected by retro-orbital bleed between weeks 16 and 18 using a non-heparinized capillary tube, and insulin, adiponectin, and leptin were measured as described previously (29). Serum cytokines (MCP-1, TNF- $\alpha$, and IL-6) were measured using a multiplexed bead-based immunoassay (BD Biosciences) following 
the manufacturer's instructions. Hyperinsulinemic-euglycemic clamps were performed on conscious mice after 22 weeks of feeding as recently described $(54,67)$. After the hyperinsulinemic-euglycemic clamp, adipose tissue macrophages were isolated from epididymal adipose tissue following collagenase digestion (Liberase enzyme; Roche) and isolated using a Mouse CD11b Positive Selection Kit (STEMCELL Technologies). Cells were then lysed in TRIzol reagent (Invitrogen), and RNA was extracted for qRT-PCR as described previously (29). Immunoblotting of tissues was performed using antibodies and procedures as described $(29,68)$.

CT scanning. Adiposity was determined using CT scanning after 20 weeks of feeding as described previously (69). Briefly, mice were anesthetized with isoflurane gas, and images were acquired on an X-SPECT (Gamma Medica) within the McMaster Centre for Pre-Clinical and Translational Imaging. A water-filled tube was included with each scan as a calibrator for Hounsfield units (HU). CT images were analyzed using Amira software (version 5.2.2; Visage Imaging), and the whole-body adipose volume was segmented using a computer-assisted application selecting a range of volume from -450 to $-125 \mathrm{HU}$. To facilitate use of volume segmentation tools, digital Gaussian filtering (kernel 3, sigma value 0.67 ) was employed to smooth the threedimensional, HU-calibrated CT images. Density histograms of the volume within the selected range $(-450$ to $-125 \mathrm{HU})$ were generated, and the total volume of adipose tissue was calculated by summation of the total density.

Immunohistochemistry. Paraffin-embedded epididymal fat and liver were sectioned, dewaxed, and rehydrated prior to antigen retrieval by boiling in $10 \mathrm{mM}$ sodium citrate buffer ( $\mathrm{pH}$ 6.5). Endogenous peroxidase was quenched by treatment with $3 \% \mathrm{H}_{2} \mathrm{O}_{2}$ in PBS. Tissue samples were blocked with $5 \%$ normal rabbit serum for 40 minutes, followed by blocking of endogenous biotin and avidin binding sites using the Biotin/Avidin blocking kit form Vector Laboratories. Sections were incubated for 2 hours with $10 \mu \mathrm{g} / \mathrm{ml}$ rat anti-mouse F4/80 antibody (AbD Serotec). Biotin-conjugated secondary anti-rat antibody was applied for 1 hour, followed by $30 \mathrm{~min}$ utes incubation with Vectastain ABC solution (Vector Laboratories). The sections were developed using the DAB substrate kit (Vector Laboratories) and counterstained with Mayer's hematoxylin. The total number of nuclei and the number of nuclei of F4/80-positive cells were counted in a total of 12-14 different $\times 20$ fields from three different sections for each genotype. The percentage of $\mathrm{F} 4 / 80$-positive cells for each sample was calculated as the number of nuclei of F4/80-expressing cells divided by the total number of nuclei per sample. Liver F4/80 staining was quantified using ImageJ (http://rsbweb.nih.gov/ij/) and the color segmentation plug-in.

Cell culture. WT and $\beta 1^{-/-}$bone marrow was isolated from the femur and tibia of 10- to 12-week-old mice as described previously (56). For palmitate treatments, day-8 BMDMs were serum starved 3-4 hours before incubation with the indicated palmitate concentrations at the indicated times, conjugated to $2 \%(\mathrm{w} / \mathrm{v})$ fatty acid-free and low endotoxin BSA (SigmaAldrich). BMDMs were pretreated with $50 \mu \mathrm{M}$ etomoxir (Sigma-Aldrich), $50 \mu \mathrm{M}$ rotenone (Sigma-Aldrich), $500 \mu \mathrm{M}$ dinitrophenol (Sigma-Aldrich), or A769662 (Ascent Scientific) for 2 hours before the addition of assay medium containing palmitate. Compounds were subsequently replenished into the medium and kept present throughout the incubation period with palmitate. Mitochondria were depleted from WT BMDMs by treatment with $0.4 \mu \mathrm{g} / \mathrm{ml}$ ethidium bromide (Bio-Rad) for 48 hours prior to experiments and replenished throughout the experimental incubations with palmitate. To examine fatty acid oxidation and incorporation into lipid pools, BMDMs were incubated with $\left[1-{ }^{14} \mathrm{C}\right]$ palmitic acid $(0.5 \mu \mathrm{Ci} / \mathrm{ml})$ (Amersham Biosciences) and $0.2 \mathrm{mM}$ unlabeled palmitate for 4 hours as described previously (70). For gene expression analysis, cells were left untreated or incubated with $0.5 \mathrm{mM}$ palmitate for 6 or 24 hours and subsequently lysed in TRIzol reagent (Invitrogen), and RNA was extracted for qRT-PCR as described previously (35). Immunoblotting and AMPK $\alpha 1$ activity assays of cellular lysates were performed using antibodies and procedures as previously described $(29,68)$. BMDM supernatants were analyzed for the presence of cytokines (IL-1 $\beta$, IL-6, TNF- $\alpha$ ) after overnight incubation of cells with $0.5 \mathrm{mM}$ palmitate using a multiplexed bead-based immunoassay (Mouse Inflammation Kit) from BD Biosciences.

Isolation and preparation of peritoneal macrophages for flow cytometry. Alexa Fluor 488-labeled antibody specific for AMPK phosphorylated on $\alpha \mathrm{T} 172$ (24) was produced using the DyLight 488 Antibody Labeling Kit from Pierce Biotechnology (Rockford). Resident peritoneal cells were harvested from control and $o b / o b$ mice, and $\mathrm{F} 4 / 80^{+} \mathrm{CD} 11 \mathrm{~b}^{+}$cells were separated from the remainder of the peritoneal cell population using a FACSAria cell sorter (BD Biosciences) as described previously (56). For assessment of T cell populations, phycoerythrin-CD4 (PE-CD4, $0.8 \mu \mathrm{g} / \mathrm{ml}$ ) and Alexa Fluor 700-CD3 (A700-CD3, $0.8 \mu \mathrm{g} / \mathrm{ml}$ ) were purchased from eBioscience. For intracellular Foxp 3 staining, $\mathrm{CD}^{+} \mathrm{CD}^{+}$cells were processed according to the manufacturer's instructions using the Anti-Mouse/Rat Foxp3 FITC Staining Set from eBioscience. Following incubation, cells were analyzed using a FACSCalibur flow cytometer (BD Biosciences) and CellQuest software (BD Biosciences). Gates and compensations were set by using unstained, single-stained, and fluorescence-minus-one control.

Conditioned medium experiments. For conditioned medium experiments, primary hepatocytes were isolated as described previously (71). BMDMs were prepared as above and incubated with $0.5 \mathrm{mM}$ palmitate for 6 hours. Cells were then washed with PBS and recovered in serum-free Williams medium E (Invitrogen) supplemented with $1 \%$ antibiotic-antimycotic (Gibco, Invitrogen) for 12 hours. This medium was then removed from BMDMs and transferred onto WT primary hepatocytes for 3 hours. Cells were then harvested for determination of inflammatory gene expression or incubated with $10 \mathrm{nM}$ insulin for a further 4 hours for the determination of gluconeogenic gene expression as described previously (67).

Statistics. All results are shown as mean \pm SEM. Results were analyzed using a 2-tailed Student's $t$ test or 1- or 2-way ANOVA where appropriate, using GraphPad Prism software. A Bonferonni post hoc test was used to test for significant differences revealed by the ANOVA. Significance was accepted at $P \leq 0.05$.

Study approval. All experimental protocols used in this study were approved by the St. Vincent's Hospital and McMaster University Animal Ethics Committees.

\section{Acknowledgments}

These studies were supported by grants and fellowships from the National Health and Medical Research Council (to B.E. Kemp and G.R. Steinberg), the Canadian Diabetes Association (CDA), and the Canadian Institutes of Health Research (CIHR) (to G.R. Steinberg). G.R. Steinberg is a Canada Research Chair in Metabolism and Obesity. M.D. Fullerton is a CIHR Banting Postdoctoral Fellow. J.D. Schertzer is a DeGroote Academic Fellow (McMaster University) and is supported by a CDA fellowship. We thank Kimberly Hewitt, Deelan Patel, and Palanivel Rengasamy for technical assistance and Chantal Saab of the McMaster Centre for Translational Imaging for completing the CT analysis.

Received for publication April 18, 2011, and accepted in revised form October 5, 2011.

Address correspondence to: Gregory R. Steinberg, Division of Endocrinology and Metabolism, Department of Medicine, HSC 4N63, McMaster University, 1280 Main St. West, Hamilton, Ontario, L8N 3Z5, Canada. Phone: 905.521.2100, ext. 21691; Fax: 905.777.7856; E-mail: gsteinberg@mcmaster.ca. 
1. Hotamisligil GS, Shargill NS, Spiegelman BM. Adipose expression of tumor necrosis factor-alpha: direct role in obesity-linked insulin resistance. Science. 1993;259(5091):87-91.

2. Steinberg GR, et al. Tumor necrosis factor alphainduced skeletal muscle insulin resistance involves suppression of AMP-kinase signaling. Cell Metab. 2006;4(6):465-474.

3. Ghanim H, Aljada A, Hofmeyer D, Syed T, Mohanty $\mathrm{P}$, Dandona P. Circulating mononuclear cells in the obese are in a proinflammatory state. Circulation. 2004;110(12):1564-1571.

4. Weisberg SP, McCann D, Desai M, Rosenbaum M, Leibel RL, Ferrante AW Jr. Obesity is associated with macrophage accumulation in adipose tissue. J Clin Invest. 2003;112(12):1796-1808.

5. Xu H, et al. Chronic inflammation in fat plays a crucial role in the development of obesity-related insulin resistance. J Clin Invest. 2003;112(12):1821-1830.

6. Arkan MC, et al. IKK-beta links inflammation to obesity-induced insulin resistance. Nat Med. 2005; 11(2):191-198.

7. Solinas G, et al. JNK1 in hematopoietically derived cells contributes to diet-induced inflammation and insulin resistance without affecting obesity. Cell Metab. 2007;6(5):386-397.

8. Nguyen MT, et al. A subpopulation of macrophages infiltrates hypertrophic adipose tissue and is activated by free fatty acids via Toll-like receptors 2 and 4 and JNK-dependent pathways. J Biol Chem. 2007;282(48):35279-35292.

9. Suganami T, et al. Role of the Toll-like receptor 4/NF-kappaB pathway in saturated fatty acidinduced inflammatory changes in the interaction between adipocytes and macrophages. Arterioscler Thromb Vasc Biol. 2007;27(1):84-91.

10. Tsukumo DM, et al. Loss-of-function mutation in Toll-like receptor 4 prevents diet-induced obesity and insulin resistance. Diabetes. 2007;56(8):1986-1998.

11. Saberi M, et al. Hematopoietic cell-specific deletion of toll-like receptor 4 ameliorates hepatic and adipose tissue insulin resistance in high-fat-fed mice. Cell Metab. 2009;10(5):419-429.

12. Lumeng CN, Bodzin JL, Saltiel AR. Obesity induces a phenotypic switch in adipose tissue macrophage polarization. J Clin Invest. 2007;117(1):175-184

13. Lumeng CN, Deyoung SM, Bodzin JL, Saltiel AR. Increased inflammatory properties of adipose tissue macrophages recruited during diet-induced obesity. Diabetes. 2007;56(1):16-23.

14. Hevener AL, et al. Macrophage PPAR gamma is required for normal skeletal muscle and hepatic insulin sensitivity and full antidiabetic effects of thiazolidinediones. J Clin Invest. 2007;117(6):1658-1669.

15. Odegaard JI, et al. Macrophage-specific PPARgamma controls alternative activation and improves insulin resistance. Nature. 2007;447(7148):1116-1120.

16. Kang K, et al. Adipocyte-derived Th2 cytokines and myeloid PPARdelta regulate macrophage polarization and insulin sensitivity. Cell Metab. 2008 . $7(6): 485-495$.

17. Odegaard JI, et al. Alternative M2 activation of Kupffer cells by PPARdelta ameliorates obesity-induced insulin resistance. Cell Metab. 2008; 7(6):496-507.

18. Vats D, et al. Oxidative metabolism and PGC-1beta attenuate macrophage-mediated inflammation. Cell Metab. 2006;4(1):13-24.

19. Furuhashi M, et al. Treatment of diabetes and atherosclerosis by inhibiting fatty-acid-binding protein aP2. Nature. 2007;447(7147):959-965.

20. Makowski L, et al. Lack of macrophage fatty-acidbinding protein aP2 protects mice deficient in apolipoprotein E against atherosclerosis. Nat Med. 2001;7(6):699-705.

21. Koliwad SK, et al. DGAT1-dependent triacylglycerol storage by macrophages protects mice from diet-induced insulin resistance and inflammation.
J Clin Invest. 2010;120(3):756-767.

22. Merrill GF, Kurth EJ, Hardie DG, Winder WW. AICA riboside increases AMP-activated protein kinase, fatty acid oxidation, and glucose uptake in rat muscle. Am J Physiol. 1997;273(6 pt 1):E1107-E1112.

23. Steinberg GR, Kemp BE. AMPK in health and disease. Physiol Rev. 2009;89(3):1025-1078.

24. Winder WW, Holmes BF, Rubink DS, Jensen EB, Chen M, Holloszy JO. Activation of AMP-activated protein kinase increases mitochondrial enzymes in skeletal muscle. J Appl Physiol. 2000;88(6):2219-2226.

25. Zong $\mathrm{H}$, et al. AMP kinase is required for mitochondrial biogenesis in skeletal muscle in response to chronic energy deprivation. Proc Natl Acad Sci US A. 2002;99(25):15983-15987.

26. Jorgensen SB, et al. Effects of alpha-AMPK knockout on exercise-induced gene activation in mouse skeletal muscle. FASEB J. 2005;19(9):1146-1148.

27. Jager S, Handschin C, St-Pierre J, Spiegelman BM. AMP-activated protein kinase (AMPK) action in skeletal muscle via direct phosphorylation of PGC-1alpha. Proc Natl Acad Sci U S A. 2007; 104(29):12017-12022.

28. Canto C, et al. AMPK regulates energy expenditure by modulating NAD + metabolism and SIRT1 activity. Nature. 2009;458(7241):1056-1060.

29. Watt MJ, et al. CNTF reverses obesity-induced insulin resistance by activating skeletal muscle AMPK. Nat Med. 2006;12(5):541-548.

30. Gauthier MS, et al. Decreased AMP-activated protein kinase activity is associated with increased inflammation in visceral adipose tissue and with whole-body insulin resistance in morbidly obese humans. Biochem Biophys Res Commun. 2010; 404(1):382-387.

31. Sag D, Carling D, Stout RD, Suttles J. Adenosine 5 -monophosphate-activated protein kinase promotes macrophage polarization to an anti-inflammatory functional phenotype. J Immunol. 2008; 181(12):8633-8641

32. Yang Z, Kahn BB, Shi H, Xue BZ. Macrophage \{alpha\}1-AMP-activated protein kinase (\{alpha\}1AMPK) antagonizes fatty acid-induced inflammation through SIRT1. J Biol Chem. 2010; 285(25):19051-19059.

33. Jeong HW, et al. Berberine suppresses proinflammatory responses through AMPK activation in macrophages. Am J Physiol Endocrinol Metab. 2009; 296(4):E955-E964

34. Welsh N. Interleukin-1 beta-induced ceramide and diacylglycerol generation may lead to activation of the c-Jun NH2-terminal kinase and the transcription factor ATF2 in the insulin-producing cell line RINm5F. J Biol Chem. 1996;271(14):8307-8312.

35. Watt MJ, Steinberg GR, Chen ZP, Kemp BE, Febbraio MA. Fatty acids stimulate AMP-activated protein kinase and enhance fatty acid oxidation in L6 myotubes. J Physiol. 2006;574(pt 1):139-147.

36. Cani PD, et al. Metabolic endotoxemia initiates obesity and insulin resistance. Diabetes. 2007; 56(7):1761-1772

37. Cool B, et al. Identification and characterization of a small molecule AMPK activator that treats key components of type 2 diabetes and the metabolic syndrome. Cell Metab. 2006;3(6):403-416.

38. Scott JW, et al. Thienopyridone drugs are selective activators of AMP-activated protein kinase beta1-containing complexes. Chem Biol. 2008; 15(11):1220-1230.

39. Hayakawa T, et al. Ethidium bromide-induced inhibition of mitochondrial gene transcription suppresses glucose-stimulated insulin release in the mouse pancreatic beta-cell line betaHC9.J Biol Chem. 1998;273(32):20300-20307.

40. Leibowitz RD. The effect of ethidium bromide on mitochondrial DNA synthesis and mitochondrial DNA structure in HeLa cells. J Cell Biol. 1971; 51(1):116-122.
41. Gan B, et al. Lkb1 regulates quiescence and metabolic homeostasis of haematopoietic stem cells. Nature. 2010;468(7324):701-704.

42. Gurumurthy S, et al. The Lkb1 metabolic sensor maintains haematopoietic stem cell survival. Nature. 2010;468(7324):659-663.

43. Nakada D, Saunders TL, Morrison SJ. Lkb1 regulates cell cycle and energy metabolism in haematopoietic stem cells. Nature. 2010;468(7324):653-658.

44. Nishimura S, et al. CD8+ effector T cells contribute to macrophage recruitment and adipose tissue inflammation in obesity. Nat Med. 2009;15(8):914-920.

45. Winer S, et al. Normalization of obesity-associated insulin resistance through immunotherapy. Nat Med. 2009;15(8):921-929.

46. Feuerer $M$, et al. Lean, but not obese, fat is enriched for a unique population of regulatory $\mathrm{T}$ cells that affect metabolic parameters. Nat Med. 2009;15(8):930-939.

47. Kirchgessner TG, Uysal KT, Wiesbrock SM, Marino MW, Hotamisligil GS. Tumor necrosis factor-alpha contributes to obesity-related hyperleptinemia by regulating leptin release from adipocytes. J Clin Invest. 1997;100(11):2777-2782.

48. Zumbach MS, Boehme MW, Wahl P, Stremmel W, Ziegler R, Nawroth PP. Tumor necrosis factor increases serum leptin levels in humans. J Clin Endocrinol Metab. 1997;82(12):4080-4082.

49. Maeda N, et al. PPARgamma ligands increase expression and plasma concentrations of adiponectin, an adipose-derived protein. Diabetes. 2001; 50(9):2094-2099.

50. Howard JK, Cave BJ, Oksanen LJ, Tzameli I, Bjorbaek C, Flier JS. Enhanced leptin sensitivity and attenuation of diet-induced obesity in mice with haploinsufficiency of Socs3. Nat Med. 2004;10(7):734-738.

51. Ozcan L, et al. Endoplasmic reticulum stress plays a central role in development of leptin resistance. Cell Metab. 2009;9(1):35-51.

52. Zhang X, Zhang G, Zhang H, Karin M, Bai H, Cai D. Hypothalamic IKKbeta/NF-kappaB and ER stress link overnutrition to energy imbalance and obesity. Cell. 2008;135(1):61-73.

53. Prieur X, et al. Differential lipid partitioning between adipocytes and tissue macrophages modulates macrophage lipotoxicity and M2/M1 polarization in obese mice. Diabetes. 2011;60(3):797-809.

54. Dzamko N, et al. AMPK beta1 deletion reduces appetite, preventing obesity and hepatic insulin resistance. J Biol Chem. 2010;285(1):115-122.

55 . Kosteli A, et al. Weight loss and lipolysis promote a dynamic immune response in murine adipose tissue. J Clin Invest. 2010;120(10):3466-3479.

56. Sachithanandan $\mathrm{N}$, et al. Macrophage deletion of SOCS1 increases sensitivity to LPS and palmitic acid and results in systemic inflammation and hepatic insulin resistance. Diabetes. 2011; 60(8):2023-2031

57. Vieira VJ, Valentine RJ, Wilund KR, Antao N, Baynard T, Woods JA. Effects of exercise and low-fat diet on adipose tissue inflammation and metabolic complications in obese mice. Am J Physiol Endocrinol Metab. 2009;296(5):E1164-E1171.

58. Bradley RL, Jeon JY, Liu FF, Maratos-Flier E. Voluntary exercise improves insulin sensitivity and adipose tissue inflammation in dietinduced obese mice. Am J Physiol Endocrinol Metab. 2008;295(3):E586-E594

59. Lin HZ, Yang SQ, Chuckaree C, Kuhajda FP, Ronnet G, Diehl AM. Metformin reverses fatty liver disease in obese, leptin-deficient mice. Nature medicine. 2000;6(9):998-1003.

60. Zhou G, et al. Role of AMP-activated protein kinase in mechanism of metformin action. J Clin Invest. 2001;108(8):1167-1174

61. Fryer LG, Parbu-Patel A, Carling D. The Anti-diabetic drugs rosiglitazone and metformin stimulate AMPactivated protein kinase through distinct signaling 
pathways. J Biol Chem. 2002;277(28):25226-25232.

62. Winder WW, Hardie DG. Inactivation of acetylCoA carboxylase and activation of AMP-activated protein kinase in muscle during exercise. $A m \mathrm{~J}$ Physiol. 1996;270(2 pt 1):E299-E304.

63. Cacicedo JM, Gauthier MS, Lebrasseur NK, Jasuja $\mathrm{R}$, Ruderman NB, Ido Y. Acute exercise activates AMPK and eNOS in the mouse aorta. Am J Physiol Heart Circ Physiol. 2011;301(4):H1255-H1265.

64. Carlson CL, Winder WW. Liver AMP-activated protein kinase and acetyl-CoA carboxylase during and after exercise. J Appl Physiol. 1999;86(2):669-674.

65. Park H, et al. Coordinate regulation of malonylCoA decarboxylase, sn-glycerol-3-phosphate acyl- transferase, and acetyl-CoA carboxylase by AMPactivated protein kinase in rat tissues in response to exercise. J Biol Chem. 2002;277(36):32571-32577.

66. Quinn JM, et al. Germline deletion of AMP-activated protein kinase beta subunits reduces bone mass without altering osteoclast differentiation or function. FASEB J. 2010;24(1):275-285.

67. Sachithanandan $\mathrm{N}$, et al. Liver-specific suppressor of cytokine signaling-3 deletion in mice enhances hepatic insulin sensitivity and lipogenesis resulting in fatty liver and obesity. Hepatology. 2010;52(5):1632-1642.

68. Beck Jorgensen S, O’Neill HM, Hewitt K, Kemp BE, Steinberg GR. Reduced AMP-activated protein kinase activity in mouse skeletal muscle does not exacerbate the development of insulin resistance with obesity. Diabetologia. 2009;52(11):2395-2404.

69. Jobse BN, et al. Evaluation of allergic lung inflammation by computed tomography in a rat model in vivo. Eur Respir J. 2009;33(6):1437-1447.

70. Chen MB, et al. Impaired activation of AMP-kinase and fatty acid oxidation by globular adiponectin in cultured human skeletal muscle of obese type 2 diabetics. J Clin Endocrinol Metab. 2005;90(6):3665-3672.

71. Fullerton MD, Hakimuddin F, Bonen A, Bakovic M. The development of a metabolic disease phenotype in CTP:phosphoethanolamine cytidylyltransferase-deficient mice. J Biol Chem. 2009;284(38):25704-25713. 